\title{
Transcriptional control of chondrocyte specification and differentiation
}

\author{
Chia-Feng Liu ${ }^{1,{ }^{*}}$, William E. Samsa ${ }^{2}$, Guang Zhou ${ }^{2,3,4}$, and Véronique Lefebvre ${ }^{1,{ }^{*}}$ \\ ${ }^{1}$ Department of Cellular and Molecular Medicine, Cleveland Clinic Lerner Research Institute, \\ Cleveland, $\mathrm{OH}, 44195$, USA \\ ${ }^{2}$ Department of Orthopaedics, Case Western Reserve University, Cleveland, OH, USA \\ ${ }^{3}$ Department of Genetics and Genome Sciences, Case Western Reserve University, Cleveland, \\ $\mathrm{OH}, \mathrm{USA}$ \\ ${ }^{4}$ Case Comprehensive Cancer Center, Case Western Reserve University, Cleveland, OH, USA
}

\section{Abstract}

A milestone in the evolutionary emergence of vertebrates was the invention of cartilage, a tissue that has key roles in modeling, protecting and complementing the bony skeleton. Cartilage is elaborated and maintained by chondrocytes. These cells derive from multipotent skeletal progenitors and they perform highly specialized functions as they proceed through sequential lineage commitment and differentiation steps. They form cartilage primordia, the primary skeleton of the embryo. They then transform these primordia either into cartilage growth plates, temporary drivers of skeletal elongation and endochondral ossification, or into permanent tissues, namely articular cartilage. Chondrocyte fate decisions and differentiated activities are controlled by numerous extrinsic and intrinsic cues, and they are implemented at the gene expression level by transcription factors. The latter are the focus of this review. Meritorious efforts from many research groups have led over the last two decades to the identification of dozens of key chondrogenic transcription factors. These regulators belong to all types of transcription factor families. Some have master roles at one or several differentiation steps. They include SOX 9 and RUNX2/3. Others decisively assist or antagonize the activities of these masters. They include TWIST1, SOX5/6, and MEF2C/D. Many more have tissue-patterning roles and regulate cell survival, proliferation and the pace of cell differentiation. They include, but are not limited to, homeodomain-containing proteins and growth factor signaling mediators. We here review current knowledge of all these factors, one superclass, class, and family at a time. We then compile all knowledge into transcriptional networks. We also identify remaining gaps in knowledge and directions for future research to fill these gaps and thereby provide novel insights into cartilage disease mechanisms and treatment options.

\footnotetext{
*Corresponding authors: Chia-Feng Liu (liuc2@ccf.org), Véronique Lefebvre (lefebvv@ccf.org), Department of Cellular \& Molecular Medicine, Cleveland Clinic Lerner Research Institute, 9500 Euclid Avenue, NC-10, Cleveland, OH, 44195, USA.

Publisher's Disclaimer: This is a PDF file of an unedited manuscript that has been accepted for publication. As a service to our customers we are providing this early version of the manuscript. The manuscript will undergo copyediting, typesetting, and review of the resulting proof before it is published in its final citable form. Please note that during the production process errors may be discovered which could affect the content, and all legal disclaimers that apply to the journal pertain.
} 


\section{Keywords}

Cartilage; cell lineage; differentiation; master regulator; specification; transcription

\section{Introduction}

Chondrogenesis is a critical process in the development and healthy maintenance of the vertebrate skeleton [1]. It consists in generating chondrocytes and in directing these cells through successive steps of commitment and differentiation in order to build, renew or remodel cartilage tissues in a tightly controlled spatial and temporal manner. Deciphering the cellular and molecular mechanisms that drive and regulate chondrogenesis is a prerequisite to decoding the causes of the various types of cartilage diseases that affect humans and to developing highly needed treatments for these diseases. Among these diseases, chondrodysplasias are fairly rare, but exist in hundreds of forms [2]. They vary from mild malformations of discrete skeletal elements to generalized skeletal malformations that can be lethal in the perinatal period or result in dwarfism. Osteoarthritis, in contrast, is a highly prevalent, adult-onset disease, primarily characterized by progressive, irreversible degeneration of articular cartilage [3].

Chondrocytes arise in development from multipotent skeletogenic progenitor/stem cells (SSCs), which themselves derive from embryonic cranial neural crest and from paraxial and lateral plate mesoderm. SSCs give rise to two main types of chondrocytes. They become growth plate chondrocytes (GPCs) by proceeding through an intermediate, bipotent osteochondroprogenitor (OCPs) stage (with osteoblast $[\mathrm{OB}]$ and chondrocyte potential), and become articular chondrocytes (ACCs) via a multipotent joint progenitor (JP) stage (with chondrocyte, synovial and other joint cell type potential). Once committed to either fate, prechondrocytes (PCs) coalesce into precartilaginous condensations. They next differentiate into early chondrocytes (ECs) and build cartilage primordia by proliferating and producing copious amounts of cartilage extracellular matrix (namely expressing the genes for collagen type II [COL2AI] and aggrecan $[A C A N])$. GPCs then follow multiple steps of maturation. They first continue to dynamically proliferate and produce cartilage matrix while aligning themselves in longitudinal columns. These activities allow fast and linear growth of skeletal elements and provide an orderly arranged extracellular matrix template upon which trabecular bone will later be deposited. The so-called columnar chondrocytes (CCs) undergo cell cycle arrest as they transition to prehypertrophy. While still expressing early cartilage matrix genes at maximal levels, prehypertrophic chondrocytes (PHCs) also express stagespecific markers (e.g., $I H H$, Indian hedgehog gene) and initiate expression of hypertrophic markers (e.g., COL10A1, collagen type 10 gene). They have a central regulatory role in skeleton development. They emit signals, namely IHH and non-canonical WNTs (including WNT5A), that stimulate CC proliferation and alignment, respectively. IHH also regulates the pace of GPC maturation and induces cortical bone formation in adjacent perichondrium. Next, hypertrophic chondrocytes (HCs) massively expand their cytoplasmic volume and fully switch to a new genetic program. They are as important as CCs to elongate skeletal elements. In addition, they contribute to endochondral ossification (EO) by modifying the cartilage matrix and emitting such signals as the vascular endothelial growth factor VEGFA. 
At the end of the GPC journey, terminal chondrocytes (TCs) express an osteoblast-like phenotype, remodeling and mineralizing the cartilage matrix (e.g., expressing the genes for the bone sialoprotein $[I B S P]$ and matrix metalloproteinase 13 [MMP13]). They eventually die or fully adopt the OB fate in nascent endochondral bone. Compared to the highly dynamic and transient GPC program, the ACC pathway appears as a conservative one. ACCs proliferate and productively assemble extracellular matrix as they develop their tissue. Once articular cartilage (AC) acquires its adult size, ACCs hardly ever proliferate and they limit their activity to turning over a subset of extracellular matrix components, including aggrecan, but not collagens. Their tissue features layers that are reminiscent of growth plate (GP) zones in terms of differential extracellular matrix composition and cell morphology, but it remains unclear how ACCs form these layers. One school of thought is that the tissue grows in an appositional manner, chondrocytes differentiating from JPs located near the tissue surface and arresting at progressively more mature stages as they reach the subchondral bone [1]. Another view is that JPs are initially distributed uniformly across the tissue and that ACCs directly acquire spatial specialization as they differentiate [4]. It is also unclear when and how distinctions are made between the ACC and GPC programs. As indicated earlier, SSCs appear to adopt either fate as they develop into OCPs or JPs, even though articular and growth plate ECs share many phenotypic features. ACCs are distinguished from GPCs notably by not proceeding to prehypertrophy. As a result, they are unable to elongate their tissue in a fast and considerable manner and to induce its EO. Even if the ACC and GPC programs are distinct, they are not locked. ACCs can indeed switch to the GPC fate in osteoarthritis and mature GPCs can switch to the OB fate. Chondrocyte fate and differentiation decisions are governed and influenced by many types of regulatory factors. We here focus on current knowledge and gaps in knowledge of chondrogenic transcription factors (TFs).

Chondrocytes and all other cell types co-express at any single time thousands of ubiquitous genes and hundreds of lineage-specific and differentiation stage-specific genes. An important and fascinating research enterprise is to decipher the molecular basis of the transcriptional programs that govern the specific identity and activities of each cell type. A pioneer discovery was made 30 years ago when forced expression of the transcription factor MYOD was shown to be sufficient to engage mesenchymal cells into myoblast differentiation [5]. This finding sparked the hypothesis that each cell type is ruled by a master TF, i.e., a TF necessary and sufficient for cell type specification and differentiation. Within a decade, SOX9 was cloned and postulated to be the EC master [6, 7] and RUNX2/3 the GPC masters [8-10]. It then progressively became clear that no cell type is governed by a single master TF and that, instead, cell types might be determined by cores of master TFs. These cores likely contain pioneer and classical TFs. Pioneers bind to condensed chromatin and recruit histone- and DNA-modifying enzymes that write or erase epigenetic modifications. [11]. These modifications are necessary to poise, activate or repress enhancers and promoters, and can have immediate as well as long-lasting consequences on cell lineage and subtype specification, differentiation and other activities. Once chromatin is open, classical TFs bind to enhancers and promoters, and effect gene activation or repression. SOX2, OCT3/4, KLF4 and c-MYC were discovered 10 years ago by the Yamanaka group to be necessary and sufficient to specify and maintain embryonic stem cells 
and to induce pluripotent stem cells from differentiated cell types [12]. While forming a master core, these four TFs nevertheless help themselves with many other factors. As discussed in this review, SOX 9 and RUNX2/3 also rely on many functional partners to achieve and fine-tune their chondrogenic master functions.

An important task in deciphering whether TFs directly impact gene expression is to delineate the DNA sequences (cis-acting elements) through which genes are activated and repressed. Sequences closely associated with transcription start sites (within $\sim 50 \mathrm{bp}$ ) mediate the assembly of the basal transcriptional machinery, i.e., a complex of ubiquitous factors that recruit RNA polymerase. Proximal enhancers (typically within $\sim 1 \mathrm{~kb}$ of transcription start sites) bind ubiquitous and/or cell type-specific TFs capable of interacting with the basal transcription machinery to activate or repress transcription. Remote enhancers have long been known to exist, but they were initially thought to be rare. The recent advent of wholegenome approaches, including chromatin immunoprecipitation followed by high-throughput sequencing (ChIP-seq), has revealed that they are actually very abundant and have primary roles in cell type-specific transcriptional regulation. It was first shown that the Yamanaka factors specify pluripotent stem cell identity and activities by binding primarily, not to promoters, but to enhancers located up to several hundreds of kb around promoters [13]. These remote enhancers are often found in clusters, and are therefore named superenhancers. Since then, many cell types have been shown to feature master factor-bound super-enhancers. Namely, non-hypertrophic GPCs possess several hundreds of superenhancers associated with cartilage-specific genes and bound by SOX9 $[14,15]$. These super-enhancers feature DNA motifs for multiple TF types in addition to SOX9 binding sites, and thus support the notion that SOX9 does not work alone.

To date, the prevailing model is thus that chondrocytes have their specific activities governed at the genome level by dynamic cores of master factors binding to super-enhancers and assisted by many modulatory factors binding at the level of super-enhancers, proximal enhancers and promoter regions. The human genome encodes more than $3000 \mathrm{TFs}$, categorized into superclasses, classes and families, according to the features of their DNAbinding and other functional domains [16]. We review current knowledge of chondrogenic TFs based on this classification (Table I). We end with an integrative view of their interactions during chondrocyte differentiation and with suggestions for future research.

\section{Beta-scaffold transcription factors with minor groove contacts}

We start with a superclass of TFs that feature a $\beta$-scaffold in their DNA-binding domain and that, unlike all other types of TFs, contact DNA primarily in the minor groove. This class happens to contain all currently known chondrogenic master TFs.

\subsection{High-mobility-group (HMG)-domain factors}

A major class within this first TF superclass is comprised of proteins with a characteristic, high-mobility-group (HMG)-type DNA-binding domain. This domain is comprised of $3 \mathrm{a}$ helices that fold into an L-shape and that strongly bend the DNA helix upon intercalating into its minor groove. The HMG-domain class includes the SOX and TCF/LEF families. 
2.1.1 SOX transcription factors-SOX proteins are critically involved in cell type specification and differentiation in many lineages [17]. They bind DNA to motifs matching or resembling the $\mathrm{C}[\mathrm{A} / \mathrm{T}] \mathrm{TTG}[\mathrm{A} / \mathrm{T}][\mathrm{A} / \mathrm{T}]$ sequence, and typically increase their otherwise low DNA-binding affinity and specificity through homodimerization or cooperation with specific partners.

SOX9: A first milestone in the search for chondrogenic TFs was the discovery that heterozygous mutations within and around $S O X 9$ cause campomelic dysplasia, a severe cartilage malformation syndrome $[18,19]$. Since then, many studies have revealed that SOX9 has major functions in chondrogenesis. $S O X 9$ is expressed in this process from as early as the SSC stage, but its importance at this stage remains unknown. No defects have indeed been reported in Sox 9 -null mouse limb buds (Sox ${ }^{\text {fl/fl }}$ Prx $1 C r e$ ) until SSCs are due to differentiate into PCs [20]. The SOX9 protein may thus be kept inactive in SSCs. In mouse chimeric embryos derived from a mixture of $\mathrm{Sox}^{9^{+/+}}$and $\mathrm{Sox} \mathrm{9}^{-/-}$pluripotent stem cells, Sox $9^{+/+}$SSCs formed precartilaginous condensations, whereas Sox $9^{-/-}$SSCs either died or were displaced to the outskirts of condensations [20, 21]. The target genes of SOX9 in PCs remain unknown. In contrast, SOX9 is well proven to govern cartilage primordia and GP formation by transactivating cartilage-specific genes. ChIP-seq assays have recently widened the known spectrum of SOX9 targets in non-hypertrophic GPCs, to virtually all genes for cartilage extracellular matrix components and to many genes for cartilage-specific regulatory factors $[14,15]$. SOX9 binds DNA by forming homodimers on SOX motifs oriented in opposite direction and separated by 3-4 nucleotides. It binds primarily to enhancers and associates occasionally with repressed regions and promoters. SOX9 was once thought to prevent GPC maturation. This notion was mainly based on the fact that SOX 9 expression is turned off at the $\mathrm{PHC}$ to $\mathrm{HC}$ transition. Recent studies have confirmed that SOX9 is necessary to prevent premature growth arrest of CCs and activation of PHC markers, but have also revealed that the SOX9 protein remains present through the early $\mathrm{HC}$ stage and is necessary to allow HCs to undergo overt differentiation before dying or converting into OBs [22, 23]. SOX9 was proposed to repress Col10a1 in CCs by binding as a monomer in association with GLI2/3 to an upstream enhancer [24]. It was also shown to be necessary in $\mathrm{PHCs} / \mathrm{HCs}$ for Col10a1 expression and was proposed to directly activate the gene by cooperating as a homodimer with MEF2C on a proximal enhancer [23]. Besides being essential in cartilage primordia and GPs, SOX9 is also necessary to maintain a high level of aggrecan in adult AC [25]. Together, these studies and more have provided strong evidence that SOX9 is a master classical TF in PCs, ECs, GPCs and ACCs, and that it might have distinct actions at different stages of chondrocyte differentiation. The possibility that it also acts as a pioneer factor remains untested.

SOX5 and SOX6: Sox 5 and Sox 6 are co-expressed with $\operatorname{Sox} 9$ in chondrocytes. Belonging to the SOXD group, SOX5 and SOX6 are structurally and functionally very similar, but share with SOX9 (a SOXE protein) only 50\% identity in the HMG domain and, unlike SOX9, do not feature a transactivation domain. Their molecular actions thus differ from those of SOX9. Sox 5 and Sox6 are largely redundant in chondrogenesis [26, 27]. Whereas single knockout mice are born with mild defects, Sox 5/6 double-null fetuses die in utero with severe chondrodysplasia. They weakly express cartilage-specific genes, despite normal 
expression of $\operatorname{Sox} 9$, and hence fail to overtly develop cartilage primordia, GPs and AC.

Molecular assays have demonstrated that SOX5/6 homo/heterodimers bind in close proximity of SOX9 on cartilage-specific super-enhancers. They preferentially bind to pairs of SOX motifs oriented in the same direction and potentiate transactivation by strengthening SOX9 binding to target sites [14]. Forced expression of SOX5/6 and SOX9 is sufficient to convert SSCs into chondrocytes [28]. The three SOX proteins are therefore often referred to as the master chondrogenic SOX trio. SOX5 and SOX6 mutations have not been linked to major skeletal diseases in humans, but heterozygous deletions affecting $S O X 5$ cause intellectual disability, short stature and mild dysmorphism [29]. The latter traits advocate that optimal chondrogenesis requires full expression of $S O X 5$ in humans.

Other SOX proteins: SOX8, a SOXE protein closely related to SOX9, is expressed in SSCs and human adult ACCs [30, 31]. Sox 8 -null mice have osteopenia due to premature OB differentiation, but were not found to have cartilage malformations [32, 33]. This leaves open the question of a role for SOX8 in chondrocytes. SOX4, SOX11, and SOX12 (SOXC proteins) are closely related to one another, but not to SOX8/9 and SOX5/6. They are expressed strongly in SSCs and PCs, and weakly in chondrocytes [34]. They act redundantly to keep SSCs alive and they critically help delineate cartilage primordia by securing the nonchondrocytic fate of perichondrium cells and JPs [34, 35]. They are also pivotal to initiate GP formation through actions both in perichondrium cells and in GPCs [36]. Thus, SOX4/11/12 have cell- and non-cell-autonomous roles in the chondrocyte lineage, complementing and even opposing those of the SOX5/6/9 trio.

2.1.2. TCF/LEF proteins-The family of T-cell factor/lymphoid enhancer factors comprises four members: TCF7 (formerly called TCF1), TCF7L1 (TCF3), TCF7L2 (TCF4) and LEF1 [37]. In the absence of canonical WNT signals, these HMG-type TFs repress gene expression. Upon canonical WNT signaling, the transcriptional co-activator $\beta$-catenin translocates to the nucleus, binds to TCF/LEF factors, and converts them into transcriptional activators. TCF/LEF factors bind to CTTTG[A/T][A/T] DNA motifs, which match or resemble those of SOX proteins. TCF7L2 is specifically expressed in HCs, in which it may act together with RUNX2 [38, 39]. TCF7L2 was also shown to be expressed in primary osteoarthritic ACCs and to potentiate the pro-catabolic and apoptotic actions of NFrB [40]. These findings match the ability of canonical WNT signaling to promote GP maturation and AC degeneration [41].

\subsection{RUNX transcription factors}

RUNX proteins (also called core-binding factors, CBFs) have crucial roles in chondrogenesis and other processes [42]. They are composed of a a-subunit, encoded in humans by RUNX1/CBFA2, RUNX2/CBFA1, and RUNX3/CBFA3, and a $\beta$-subunit, encoded by $C B F B$. The a-subunit binds DNA to [A/G]ACC[A/G]CA motifs through its RUNT domain, and its affinity for DNA is increased by the $\beta$-subunit. Heterozygous mutations causing $R U N X 2$ haploinsufficiency cause cleidocranial dysplasia (CCD), a bone disease largely explained by master roles of RUNX2 in OBs [43]. 
RUNX2 and RUNX3-Another milestone in the search for chondrogenic master TFs was the discovery that Runx2-null mice die at birth lacking PHCs/HCs in several locations, besides also lacking all intramembranous and endochondral bones [8, 44]. Adding support to the notion of a master role for RUNX2 in GPCs, Forced expression of RUNX2 in CCs was shown to be sufficient to induce chondrocyte hypertrophy [9]. Later, Runx 2 and Runx 3 were both found to be highly expressed in $\mathrm{PHCs} / \mathrm{HCs}$, and redundant master actions were demonstrated by showing that Runx3-null mice have virtually normal GPs, whereas Runx 2/3-null fetuses fully lack maturing chondrocytes [10]. Proving cell-autonomous roles for the RUNX proteins in chondrocytes, mice inactivating Runx 2 specifically in chondrocytes ( $\mathrm{Col} 2 \mathrm{Cre}$ ) were shown to develop the same cartilage phenotype as Runx2-null mice [45]. RUNX2/3 are transcriptional activators and their targets in chondrocytes likely include prehypertrophic (Ihh), hypertrophic (Col1Oal) and terminal (Mmp13) markers, but the whole targetome of RUNX2/3 remains unknown. Besides genes co-expressed in chondrocytes and OBs, such as Mmp13 [46], it will be interesting to determine if chondrocyte-only markers, such as Col10a1 and Ihh, are truly direct targets of RUNX2/3, as suggested in vitro [10,47], and to identify how RUNX2 targets distinct genes in chondrocytes and in OBs. RUNT-domain motifs are frequent near the SOX5/6/9 binding sites in chondrocyte enhancers [14, 15], suggesting interplay between RUNX and SOX proteins.

RUNX1-Because Runx 1-null mouse embryos die from hematopoietic failure, the significance of Runx 1 expression in skeletogenesis was initially studied by transgenically rescuing Runx 1 expression in these embryos in endothelial/hematopoietic progenitors [48]. All cartilage and bone elements develop normally in these mice, except the sternum and occipital bone primordia, which show a chondrocyte maturation delay. These defects match those of Runx $2 / 3$ mutants in other primordia, and can be explained by the relative expression levels of the 3 genes in skeletal elements. Specific inactivation of Runx $1 / 2 \mathrm{in} \mathrm{limb}$ bud and sternum SSCs (PrX1Cre) or ECs (Col2Cre) confirmed that the two genes are partially redundant in sternum chondrogenesis [49]. In a recent study, Runx 1 expression was found upregulated in superficial adult ACCs upon mechanical loading and in osteoarthritis, suggesting roles for $R U N X 1$ in adult joints [50].

Taken together, studies on RUNX subunits and complementary studies on CBFB [51,52] have pointed to key roles for RUNX TFs in ECs, GPCs, and ACCs.

\subsection{MADS-domain transcription factors}

MADS-domain proteins participate in eukaryotic processes varying from homeosis in flowering plants to cell differentiation in animals. The MADS domain features a-helices, which wrap as a coiled coil around $\mathrm{CC}[\mathrm{A} / \mathrm{T}]_{6} \mathrm{GG}$ DNA motifs, and $\beta$-sheets, which provide a homodimerization interface. MEF2 proteins are transcriptional activators named after their myogenic roles, but they also contribute to other processes, including chondrogenesis [53]. MEF2C is essential in neural crest cells for craniofacial development [54]. It is coexpressed with MEF2D in GPCs, and the two proteins were shown to work together with RUNX2 and SOX9 to enhance Ihh and Col10a1 expression in PHCs/HCs [23, 55]. They 
were also proposed to target a number of other genes, but their full targetome remains to be defined.

\subsection{REL-homology-domain (RHD) transcription factors}

RHD factors act downstream of many signaling pathways. Their RHD domain contacts DNA in the major and minor grooves, and their C-terminus mediates homo/ heterodimerization. The main families, NFkB and NFATC, comprise several chondrocyte regulatory factors.

NF $\boldsymbol{K B}$ proteins-Five nuclear factor kappa-light-chain-enhancer of activated B cells

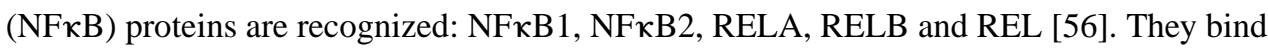
DNA to GGG[A/G]N[T/C][T/C][T/C]CC motifs. Their activation, through nuclear translocation, is induced by stress signals and inflammatory cytokines. This results in chondrocyte catabolic actions and Sox 9 downregulation [57]. In contrast, RELA/p65, which is expressed in healthy SSCs and GPCs, was shown in vitro to promote cell survival and proliferation in response to growth hormone $[58,59]$. This finding will merit in vivo validation in future studies.

NFATC proteins-Nuclear factors of activated T-cells (NFATC1 to 5) exist in vertebrates only, and they control many processes [60]. Their nuclear translocation requires dephosphorylation by the calcium-dependent calcineurin phosphatase. It occurs downstream of many signaling pathways. NFATC proteins bind DNA efficiently in partnership with such factors as AP1, GATA4, FOXP and MEF2. NFATC3 was first suggested to be involved in chondrogenesis downstream of calcineurin in a limb bud mesenchymal cell assay in vitro [61]. In vivo, NFATC1 was detected in superficial ACCs and pre/hypertrophic GPCs, and NFATC2 in adult, but not fetal ACCs [62, 63]. Interestingly, while mice lacking NFATC1 and/or NFATC 3 in chondrocytes do not show increased susceptibility to osteoarthritis, mice lacking NFATC2 do, and mice lacking NFATC1 and NFATC2 are even more susceptible. Chondrocytes in the latter mice show imbalance between anabolism and catabolism, including ectopic hypertrophy. NFATCs are thus required for AC homeostasis and might be involved in specifying the ACC versus GPC fate.

\subsection{STAT proteins}

The family of signal transducers and activators of transcription (STATs) comprises 7 members that have key roles in biological processes by regulating cell proliferation, survival, and differentiation. STAT proteins are present in a latent form in the cytoplasm, and their phosphorylation downstream of a variety of growth factors, hormones and cytokines results in homo/heterodimerization and in translocation to the nucleus. STAT proteins preferentially bind to DNA motifs containing the canonical TTC[N2-4]GAA sequence. Important roles have been proposed in chondrocytes. For instance, both STAT1 and STAT5 inhibit CC proliferation downstream of FGFR3 signaling [64, 65]. STAT5 was also implicated in mediating effects of growth hormone on GPCs [59]. STAT3 activation by pro- and antiinflammatory cytokines was shown to either negatively or positively regulate chondrocyte differentiation in vitro [66, 67]. 
These studies and many more have started to reveal that $\beta$-scaffold transcription factors with minor groove contacts have prominent, diverse actions in chondrocyte fate determination, differentiation and activities, and that full understanding of their extent and regulation should be the focus of many new research projects.

\section{Zinc-coordinating transcription factors}

Zinc-coordinating transcription factors form the largest superclass of all protein types. They account for about $50 \%$ of all human TFs and are distributed into 3 main classes [16, 68]. $\mathrm{C} 2 \mathrm{H} 2$ proteins use 2 cysteines and 2 histidines to hold a zinc ion, while C4-zinc-finger-ofnuclear-receptor-type and diverse-C4-zinc-finger proteins hold the ion with 4 cysteines. Zinc coordination stabilizes a a-helix, forming a zinc-finger that binds 3-4 nucleotides in the DNA major groove. The recognized nucleotides vary among a-helices. Most proteins feature at least 2 zinc-fingers and thus bind motifs of 6 or more nucleotides. This unique modular organization of diverse zinc-fingers provides this protein class with a large, almost infinite, spectrum of DNA-binding recognition opportunities. As such, it was ingeniously embraced by molecular biologists to custom-design zinc-finger nucleases (ZFN) for precise genomic editing [69]. Many zinc-finger proteins are expressed in the chondrocyte lineage and critically impact chondrogenesis.

\section{1. $\mathrm{C} 2 \mathrm{H} 2$ zinc-finger transcription factors}

SP/Krüppel-like (KLF) proteins form a main family in the $\mathrm{C} 2 \mathrm{H} 2$ class. They typically feature 3 zinc-fingers and work as transcriptional activators or repressors. SP1 (specificity protein 1) is ubiquitously expressed and transactivates many housekeeping, cell cycleregulated and cell type-specific genes. It was also shown in chondrocytes to bind and upregulate the promoters of Col2a1, Sox 9 , and other genes, and to be repressed by cytokines that powerfully affect chondrocytes, namely transforming growth factor- $\beta$ and interleukin-1 [70-72]. SP7/OSX is specifically expressed in PHCs and OBs. The most striking phenotype of $S p 7$-null mice is the lack of bones, explained by the fact that SP7 is a master transcriptional activator in OBs [73]. While GPs do not appear affected in these mice, mice carrying one $S p 7$ null allele and one allele inactivated in chondrocytes ( $\mathrm{Col} 2 \mathrm{Cre}$ ) delay TC maturation, suggesting that SP7 controls this process cell-autonomously [74]. ZNF521/ ZFP521 has 30 Krüppel-like zinc-fingers. Like SP7, it is expressed in PHCs and OBs, but unlike SP7, it functions as a transcriptional repressor. A target of PTHrP (parathyroid hormone-like protein) signaling, it inhibits RUNX2 activity in both cell types [75]. Its inactivation prompts chondrocyte hypertrophy, as seen in Pthlh-null mice (lacking PTHrP), and it rescues the phenotype of mice with a constitutively active PTHrP receptor (PTH1R), a model for Jansen metaphyseal chondrodysplasia [76] ZFP521 thus contributes to controlling the pace of GPC maturation.

ZBTB20/ZNF288 belongs to a family of proteins that bind DNA via both a Krüppel-type and a BTB/POZ domain. The gene for this transcriptional repressor was recently found to be strongly expressed in $\mathrm{HCs}$ and its conditional inactivation with Col2Cre to cause short stature [77]. GPC proliferation is reduced and hypertrophic zones are elongated. Sox 9 expression is prolonged and Col10a1 expression reduced. ZBTB20 is thus a newly identified 
major promoter of $\mathrm{HC}$ differentiation. Heterozygous mutation in the $Z B T B 20$ gene cause Primrose syndrome, which is characterized by recognizable facial features, macrocephaly, enlarged and calcified external ears, in addition to other non-skeletal defects \{Primrose, $1982 \# 181\}$.

SNAI1/SNAIL and SNAI2/SLUG are SNAIL-family transcriptional repressors. They have 4 and 5 zinc-fingers, respectively. They regulate many processes, including mesoderm formation and epithelial-to-mesenchymal transition [78]. Snai2 is widely expressed in the chondrocyte lineage, but Snail is mostly found in PCs and PHCs/HCs [79]. Inactivation of either gene with Prx1Cre has no obvious effect, but co-inactivation has uncovered redundant roles in GPCs. Specifically, chondrocyte proliferation is impaired, possibly due to Cdkn1a upregulation, and $\mathrm{PHC} / \mathrm{HC}$ maturation is delayed, resulting in dwarfism. SNAI1 is a target and mediator of FGFR3 signaling [80]. SNAI2 was also found to inhibit mesenchymal stem cell (MSC)-derived chondrogenesis in vitro and to be upregulated in osteoarthritic cartilage [81].

Last but not least, the GLI family of $\mathrm{C} 2 \mathrm{H} 2$ zing-finger TFs is composed of three members in mammals (GLI1-3) that are central mediators of Hedgehog signaling [82]. Gli2-null mice show, like Ihh-null mice, an elongated hypertrophic zone and reduced bone formation, whereas Gli3 inactivation rescues the defects of $I h h$-null mice. These findings indicate that GLI2 is a main mediator and GLI3 a negative regulator of the Hedgehog pathway in GPCs. AS described earlier, GLI factors cooperate with SOX9, RUNX2 and other TFs in chondrocyte transcriptional regulation.

Altogether, many studies agree that $\mathrm{C} 2 \mathrm{H} 2 \mathrm{TFs}$ have important and varied roles at all chondrocyte differentiation steps. Research must be pursued to reveal their entire targetomes and their specific positions in chondrogenic regulatory networks.

\subsection{Transcription factors with a nuclear receptor-type $\mathbf{C} 4$ zinc-finger}

Nuclear receptors are unique to metazoans. They are encoded by 49 genes in humans and have key roles in development and adulthood. Some class members are translocated to the nucleus upon ligand binding. Others are already nuclear in the absence of ligand, and are converted from transcriptional repressors to transcriptional activators upon ligand binding. Nuclear receptors recognize their targets at hormone response elements (HREs). These elements are composed of two repeats of 6 nucleotides, whose relative orientation (direct or inverted) and proximity are specific to each type of nuclear receptor.

The glucocorticoid receptor ( $N R 3 C 1$ ) is expressed ubiquitously and controls many physiological and pathological processes. It is dispensable in GPCs and ACCs in mice under physiological conditions $[83,84]$, but its over-activation in children treated with glucocorticoids likely underlies the deleterious effects observed on GPs [85]. In contrast, the thyroid hormone receptors $\alpha$ and $\beta$ (NR1A1 and A2) are critical for normal skeletal growth [86]. Both genes are expressed in GPCs. Interestingly, while Nr1a1-null mice exhibit features of hypothyroidism, including impaired GPC maturation and growth retardation, Nr1a2-null mice show signs of hyperthyroidism, including accelerated GPC maturation and short stature. The retinoic acid receptors $\alpha, \beta$ and $\gamma$ (NR1B1 to B3) are expressed in all 
GPCs, except HCs [87]. Their inactivation using Col2Cre has revealed redundancy in promoting chondrocyte proliferation and cartilage matrix production postnatally. Interestingly, since the GP is largely devoid of retinoid ligand, the receptors most likely work as ligand-free transcriptional repressors under physiological conditions. Their targets were proposed to include $S \circ x$. The peroxisome proliferator-activated receptors a, $\beta / \delta$ and $\gamma$ (PPARA, $D$, and $G$, respectively) have key roles in lipid and glucose metabolism in many cells, and PPAR $\gamma$ is an adipogenic master. Inactivation of Pparg in chondrocytes during development leads to dwarfism, with reduced expression of Sox9, Col2a1, Acan, Ihh and Col10a1 [88], and inactivation in adulthood exacerbates the development of posttraumatic osteoarthritis, at least in part by increasing cartilage catabolism [89]. In contrast, inactivation of PPAR $\delta$ has no obvious effect on cartilage development and protects mice from developing post-traumatic osteoarthritis [90]. The importance of PPARa in chondrocytes in vivo remains unknown.

Nuclear hormone receptors are thus important regulators of chondrocyte activities. Their direct and indirect actions in the cell type-specific transcriptional networks remain underestimated and deserve further studies.

\subsection{Diverse C4-type zinc-finger transcription factors}

GATA1-6 are transcriptional activators that use two zinc-fingers to bind to [A/T]GATA[A/G] DNA motifs [91]. Only GATA6 is expressed during chondrogenesis. Mainly found in SSCs and PCs, it prevents ectopic expression of Shh (Sonic Hedgehog) and hence polydactyly [92, 93]. Heterozygous mutations in the gene for one of its relatives, TRPS1, cause TrichoRhino-Phalangeal syndrome, characterized by short stature and craniofacial abnormalities. Trps 1 is expressed in PCs, perichondrium cells, JPs, and PHCs [94]). TRPS1 is a transcriptional repressor that facilitates the PHC to HC transition. It may downregulate Ihh (Indian hedgehog) and Runx2 expression by interacting with RUNX2 [94] and GLI3 [95]. Future studies will likely uncover additional targets and functional partners.

\section{Helix-turn-helix transcription factors}

Helix-turn-helix (HTH) proteins form the second largest superclass of TFs [16]. They arose in prokaryotes and represent $25 \%$ of all human TFs. The HTH domain is composed of two a-helices linked by a short "turn" sequence. One helix recognizes a specific DNA sequence and the other stabilizes DNA binding. Several classes of HTH proteins contain members importantly involved in chondrogenesis.

\subsection{Homeodomain transcription factors}

The homeodomain preferentially binds DNA to ATTA-containing motifs and is found in homeotic factors (hence its name) and many types of non-homeotic TFs [96].

The fly was the first animal found to rely on a cluster of homeobox genes (HOX) to specify the formation of antennas, legs and other body structures. Mammals were later found to have 39 HOX genes, distributed in 4 paralogous clusters. As in flies, the mammalian HOX genes have decisive, overlapping roles in body plan formation along the anterior-posterior axis. This includes specification of positional identity in the axial and appendicular skeleton [97]. 
Most HOX genes are expressed in SSCs and perichondrium cells, and not in differentiated chondrocytes [98]. Their inactivation causes agenesis or homeosis of specific structures. For instance, mouse Hox 13 inactivation prevents autopod skeletogenesis because SSCs fail to form digital precartilaginous condensation [99], and mouse Hox11 inactivation transforms the sacrum into lumbar vertebrae [100]. Mutations in human HOX genes cause several types of skeletal malformations [101].

Many non-HOX homeodomain genes also participate in skeletogenesis. An example is SHOX (short stature homeobox). Its heterozygosity causes Leri-Weill dyschondrosteosis \{Ross, $2005 \# 182\}$, featuring short stature and skeletal dysplasia, and its nullizygosity causes Langer mesomelic dysplasia [102]. These diseases involve accelerated maturation of GPCs and premature closure of GPs. Mice lack a SHOX ortholog, but possess Shox2, a paralog of human SHOX. Deletion of Shox 2 using PrX1Cre causes severe rhizomelia, whereas deletion using Col2Cre causes a much milder phenotype [103]. These findings indicate that Shox 2 controls chondrocytes mostly at the SSC stage or non-cell-

autonomously. Another example is PRRX1/MHOX (its regulatory elements drive PrX1Cre expression), whose inactivation causes agnathia-otocephaly in humans [104] and multiple skeletal malformations in mice [105]. PRRX1 too controls chondrocytes at the SSC stage or non-cell-autonomously. $D L X 5$ and $D L X 6$ sit tail-to-tail in the genome and are expressed in SSCs, perichondrium cells, PHCs/HCs, and OBs. Mutations in human $D L X 5$ and $D L X 5 / 6$ regulatory elements cause split-hand/foot malformation (SHFM) syndrome [106], and Dlx5/6-null mice exhibit lower-to-upper-jaw homeosis, skull agenesis, delayed axial skeleton growth and ossification, and SHFM-like appendicular defects [107, 108]. Findings from transgenic overexpression of Dlx 5 in chondrocytes in wild-type and Dlx5/6-null mice suggest cell-autonomous roles for DLX5/6 in chondrocyte maturation [109]. Since, unlike RUNX2, DLX5/6 are not sufficient to initiate chondrocyte pre/hypertrophy, DLX5/6 likely act downstream of RUNX2. DLX5 and SP7 were recently suggested to pair off in OBs [110]. They might thus act similarly in chondrocytes. NKX3.2/BAPX1 is an important transcriptional repressor in chondrogenesis [111]. Its nullizygosity in humans causes spondylo-megaepiphyseal-metaphyseal dysplasia, i.e., short trunk and GP and ossification defects in the axial and appendicular skeleton [112]. Induced by SHH and maintained by bone morphogenetic protein (BMP) signaling in SSCs, NKX3.2 promotes chondrogenesis by inducing $S_{0 x} 9$ upregulation and repressing Runx2 [113]. Later, it may delay GPC maturation by repressing Runx 2 and Mef2c in CCs, and may maintain cells alive by binding to NFKB $[58,114]$. NKX3.2 expression in normal and osteoarthritic human ACCs correlates negatively with expression of markers for HCs, catabolic behavior and inflammation, suggesting important roles in maintaining AC healthy [115]. NKX3.2 might act in redundancy with relatives, namely NKX3.1, such that the contribution of NKX factors to chondrogenesis may be currently underestimated.

Overall, homeodomain-containing proteins have commanding, often overlapping or redundant roles in skeleton patterning and chondrogenesis. Most are expressed primarily in SSCs and perichondrium cells, and may thus affect chondrocytes through lasting roles (e.g., epigenetic modifications in SSCs) or through non-cell-autonomous actions (e.g., by 
activating signals in the perichondrium that impact adjacent chondrocytes). Their target genes remain scarcely known.

\subsection{Paired-domain transcription factors}

Mammals contain nine paired-domain proteins (PAX1 to 9) and all have important roles in development [116]. The paired domain preferentially binds GTCACGGT motifs and owes its name to featuring two HTH regions. Several PAX proteins additively possess a full or partial homeodomain, and the two domain types synergize to bind DNA. This is the case of PAX3 and PAX7, which act redundantly in neural crest formation and other processes [117], but not of PAX1 and PAX9, which are expressed in subsets of SSCs and are necessary for cell survival $[118,119]$. PAX proteins work as transcriptional repressors or activators by recruiting distinct sets of co-factors. Their full targetome remains unknown, but PAX1/9 were proposed to directly activate $N K X 3.2$ in the sclerotome [120]. PAX7 was recently shown to have both pioneer and classical TF functions [116]. More studies are thus needed to define the molecular actions of PAX proteins in SSCs.

\subsection{Forkhead-domain transcription factors}

Humans express 40 proteins that use a forkhead/winged-helix domain (FOX) to bind [A/ $\mathrm{C}] \mathrm{AA}[\mathrm{C} / \mathrm{T}]$ sequences in the major and minor groove of DNA. These proteins are categorized into 19 groups (FOXA to FOXS) and several are known to achieve pivotal pioneer, transactivation and transrepression functions in major processes, including skeletogenesis [121, 122].

FOXC1 and C2 were the first FOX proteins to be linked to skeletogenesis. They are expressed from mesodermal to PC stages [123, 124]. Foxc1-null and Foxc2-null mice die upon birth with craniofacial and axial skeleton malformations and multiple other abnormalities [123, 125]. Skeletal defects include early patterning and chondrocyte and OB differentiation problems. Single heterozygotes are normal, but double heterozygotes exhibit many of the single-null mouse defects, indicating functional overlap between the two factors [126]. FOXC1 was proposed to interact with GLI2 in chondrocytes to stimulate the expression of IHH target genes, including Pthlh, Ptc1, and Gli1, and may also directly upregulate Col1Oa1 [127], but further studies are required to fully uncover the cell- and noncell-autonomous actions of FOXC proteins in chondrogenesis.

Deletion of FOXA2 and A3 are expressed in EC and GPC chondrocytes and their inactivation (Col2Cre) was shown to specifically impair HC differentiation [128]. Intriguingly, FOXA2/3, like FOXC1/2, were proposed to help activate Col10a1 through a FOX recognition site, raising the possibility that several FOX groups act in redundancy or through complementary actions to promote chondrocyte hypertrophy.

Adding further complexity to the actions of FOX proteins in chondrocytes, FOXP1, P2 and $\mathbf{P 4}$ are transcriptional repressors expressed strongly in PCs and perichondrium cells and weakly in CCs [77]. Their single and compound inactivation (Col2Cre) and their overexpression in transgenic mice have revealed cooperative actions in delaying GP 
maturation and EO, possibly through inhibiting RUNX2 transcriptional activity. They may thus antagonize the actions of FOXC and FOXA proteins in skeletogenesis.

FOXO1, FOXO3, and FOXO4 are ubiquitously expressed and control oxidative stress and cell metabolism, proliferation and apoptosis in many lineages. Their inactivation using Col2Cre was shown to cause elongation of $\mathrm{HC}$ zones, a postnatal increase in body length, and progressive hyperkyphosis in adulthood [129]. Resembling those of mice lacking PTEN (inhibitor of AKT activation), these defects are consistent with the ability of AKT to phosphorylate and degrade FOXO proteins. FOXO1 and FOXO3 are highly phosphorylated in osteoarthritic ACCs, likely in response to inflammatory cytokines, and their knockdown was shown to sensitize primary chondrocytes to oxidative stress [130, 131].

Thus, at least four FOX groups have key functions in developing and adult cartilage. These findings and the frequent presence of FOX recognition motifs in chondrocyte-specific superenhancers $[14,15]$. call for further studies to fully decipher their specific molecular actions in chondrocytes and progenitors.

\subsection{Tryptophan cluster transcription factors}

A specific class of TFs is made of proteins that feature multiple highly conserved and closely spaced tryptophan residues in their HTH DNA-binding domain. Within this class, the ETS family is highly implicated in cancer, but contains at least one member, ERG, also involved in skeletogenesis. ERG is strongly expressed in PCs and JPs [132]. Its inactivation in JPs (Gdf5Cre) does not affect joint formation [133], but its transgenic overexpression (Col2a1) prevents GPC maturation and induces expression of the ACC marker tenascin-C. Interestingly, mice inactivating ERG in JPs develop osteoarthritis as they age and are more sensitive to surgically induced osteoarthritis than wild-type mice. Molecular studies have suggested that the genes for PTHrP and lubricin (encoded by Prg4, a superficial ACC marker) might be part of the ERG targetome. Together, these findings suggest that ERG may help specify the ACC fate of JPs, but may act in redundancy with relatives. Further studies are needed to fully understand the contribution and regulation of ERG and relatives in chondrogenesis.

\section{Basic-domain transcription factors}

The basic-domain protein superclass accounts for less than $10 \%$ of all human TFs, but is nevertheless critical in many lineages. Basic domains are rich in positively charged amino acids that participate in formation of a-helices and facilitate interaction with DNA. Basic domains are often associated with a dimerization domain that helps stabilize binding to DNA. This superclass is divided into basic-helix-loop-helix (bHLH), basic-leucine zipper (bZIP), and basic-helix-span-helix (bHSH) classes.

\subsection{Basic-helix-loop-helix (bHLH) transcription factors}

The bHLH motif has two a-helices joined by a loop, and it generally binds DNA to the CANNTG motif, called E box [134]. Several class members are master regulators in a discrete lineage, e.g., MYOD (myogenic), MYC (cell proliferation/oncogenic), SCX (tenogenic) and NEUROD (neurogenic). Several bHLH proteins intervene in 
chondrogenesis, but none has yet been found to meet the criteria of a master chondrogenic regulator. Several TF families comprise the bHLH class.

TWIST1 is a classical bHLH factor, whose gene is expressed in SSCs and perichondrium cells downstream of canonical WNT and NOTCH signaling. TWIST1 heterozygous mutations cause Saethre-Chotzen syndrome, characterized by short stature and craniosynostosis among other skeletal anomalies. TWIST1 homo/heterodimers inhibit differentiation of SSCs into downstream cell types, including chondrocytes [51, 135, 136]. They repress genes involved in cell specification either directly or by physically interacting with master regulators, including SOX9, RUNX2, MYOD, and PPAR $\gamma$ [137]. TWIST1 may be involved in keeping SOX9 inactive in SSCs.

The bHLH-PAS family includes the hypoxia-inducible factor HIF1a, which dimerizes with the HIF1 $\beta$ subunit (also called ARNT) through a PAS (Per-Arnt-Sim) domain. The HIF1a gene is ubiquitously expressed, but its protein product is rapidly degraded, unless oxygen levels drop below 5\%. Presumptive joint regions and the center of GPs are hypoxic and rely on HIF1a to ensure cell survival and to promote cell proliferation and differentiation [138]. HIF1a transactivates genes involved in anaerobic metabolism and proline hydroxylation (a key step in collagen synthesis), and might even directly stimulate $\operatorname{Sox} 9$ expression [139]. Besides HIF1a, the bHLH-PAS family also comprises TFs regulating the circadian rhythm, namely CLOCK, BMAL1, PER1/2 and CRY1/2. Several studies have started to reveal important roles for these factors in promoting GP activity and in ensuring adult AC healthy homeostasis $[140,141]$.

The bHLH-O family is made of bHLH proteins with distinctive Orange domain, which helps in heterodimer partner selection. Prominent members are the Hairy/Enhancer of Splitrelated HES and HEY transcriptional repressors, whose genes are direct targets of NOTCH signaling. HES1 and HES5 delay the differentiation of SSCs into chondrocytes and facilitate GPC hypertrophy ([142]. As for HIF1a, a key target might be Sox9.

The bHLH-Z family is made of bHLH proteins that dimerize through a leucine zipper. It includes SREBP1 and 2, proteins essential for cholesterol metabolism. These factors may be critical in GPCs, as suggested by the observation that chondrocyte-specific inactivation of the gene for S1P, a proprotein convertase required to cleave SREBP precursor proteins into mature forms, results in severe chondrodysplasia in the mouse, with significant downregulation of SREBP-dependent pathways [143, 144].

Taken together, these findings have started to reveal that the bHLH class, like other classes of TFs, contributes several members in the regulation the chondrocyte lineage at multiple steps and in various, yet-incompletely-defined ways.

\subsection{Basic-leucine-zipper (bZIP) transcription factors}

The ZIP domain is an amino acid sequence that is mainly made of heptad repeats, in which hydrophobic residues (often leucine) occupy every first and fourth position and stabilize protein dimers. The basic region of the domain is involved in DNA sequence recognition and the leucine-zipper in dimerization and DNA-binding stabilization. The bZIP class includes 
several closely related families. Members can homodimerize or heterodimerize with relatives in their own family or in another family.

The ATF/CREB family (activating transcription factor/cyclic AMP response element binding) is involved in cell survival, growth, and stress responses in various processes. Its members bind DNA to GTGACGT[A/C][A/G] motifs (cAMP-response element, CRE). ATF4 can function as a transcriptional activator or repressor. It is induced transcriptionally and stabilized translationally by oxidative, hypoxic, and ER stress, and has key roles in allowing cells to adapt to these conditions [145, 146]. First shown to promote collagen synthesis and cell type-specific genes in OBs, it was subsequently found to stimulate CC proliferation and PHC differentiation, namely through upregulating Ihh expression [147]. Although earlier studies suggested that ATF3 could participate in promoting HC differentiation, conditional inactivation in chondrocytes (Col2Cre), revealed that ATF3 is dispensable for cartilage development [148]. The factor, however, exacerbates post-traumatic osteoarthritis downstream of inflammatory cytokines. Other studies have suggested that ATF2 and CREB could promote GPC cell cycle progression, and that ATF6 could promote chondrocyte hypertrophy by interacting with RUNX2 [149]. BBF2H7 (encoded by CREB3L2) is a membrane-bound TF most highly expressed in CCs [150]. Creb312 ${ }^{-1-}$ mice exhibit severe chondrodysplasia due to defective expression of genes encoding proteins involved in the export of cartilage extracellular matrix proteins from the endoplasmic reticulum to the Golgi apparatus. These findings call for additional studies to fully uncover the important roles that multiple ATF/CREB TFs play, possibly often in redundancy of each other, in developing and adult cartilage.

The AP1 family is primarily comprised of JUN (c-JUN, JUNB, JUND) and FOS (c-FOS, FOSB, FOSL1/FRA1 and FOSL2/FRA2) proteins [151]. Many of these proteins are expressed in GPCs [152]. AP1 factors are activated in response to various growth factors and inflammatory cytokines, and regulate cell proliferation, differentiation and death. They bind DNA at TPA (TGA[G/C]TCA) or cAMP (TGACGTCA) consensus sequences. Homodimers of c-JUN are potent transcriptional activators, whereas FOS proteins lack a transactivation domain and partner with JUN to transactivate genes. Fos inactivation in the mouse results in postnatal growth retardation, partly due to shortening of $\mathrm{CC}$ zones at the expense of $\mathrm{HC}$ zones [153]. In contrast, global and Col2Cre-mediated inactivation of Fosl2 delays HC differentiation and results in smaller HC zones [154]. FOSL2 also enhances OB differentiation [155] and is thus one more TF promoting both GPC maturation and OB differentiation. Jun is expressed in JPs. Its inactivation using Prx1Cre was shown to block specification of these cells, resulting in cartilage primordia fusions in place of joints, but it did not otherwise affect skeletal development in utero [156]. JUN is thus necessary to repress the chondrogenic fate of JPs, but is dispensable during EC and GPC differentiation. Nevertheless, a recent study showed that a large majority of SOX9-bound genomic regions coincided with a small fraction of JUN-bound regions in non-hypertrophic GPCs [152]. In vitro assays have suggested that SOX9 and JUN are able to physically interact with one another and to additively activate a Col1Oal enhancer. More studies are needed to assess the nature and full extent of actions of the various AP1 members in chondrocytes. 
The MAF family has two members, c-MAF and MAF-B, expressed in PCs, perichondrium cells and HCs [157-159]. Inactivation of Maf mildly delays EO in mouse fetuses [158]. Like JUN, c-MAF is able to physically interact with SOX9 in vitro and to cooperate with SOX9 in transactivating a reporter gene, namely one containing a Col2al cartilage-specific enhancer [157]. The in vivo significance of these findings remains unknown, as is the possibility that c-MAF acts in partial redundancy with MAFB and other bZIP proteins. Heterozygous mutations in $M A F B$ cause multicentric carpotarsal osteolysis syndrome, mimicking juvenile rheumatoid arthritis, and also associated with minor facial anomalies and non-skeletal defects $\{$ Zankl, 2012 \#183\}.

The CCAAT-enhancer-binding protein family has six members: C/EBPa to C/EBPS. These members bind DNA to CCAAT motifs through a C-terminal bZIP domain, and transactivate genes through $\mathrm{N}$-terminal domains. $\mathrm{C} / \mathrm{EBPa}$ is a master regulator of adipogenesis, and CEBP $\beta$ is critical for macrophage function. C/EBP $\beta$ and $\delta$ are abundantly expressed at all stages of GPC differentiation [160]. Cebpb-null mice are dwarf and show reduced expression of $\mathrm{PHC} / \mathrm{HC}$ markers [161]. C/EBP $\beta$ was proposed to directly target the genes for the cyclin-dependent kinase inhibitor p57Kip2 and IHH, and to interact with RUNX2 to activate $I h h[161,162]$. C/EBP $\beta$ is also produced by ACCs, especially in osteoarthritic lesions, where it could have deleterious effects [161]. Cebpb-null mice are indeed more resistant to post-traumatic osteoarthritis than wild-type mice. In addition to further defining the molecular targets and partners of C/EBP $\beta$, it will also be important to test whether $\mathrm{C} / \mathrm{EBP} \beta$ acts in partial redundancy with close relatives.

\subsection{Basic-helix-span-helix (bHSH) transcription factors}

The bHSH class is primarily represented by the AP2 family, which contains 5 members: AP2a, $\beta, \gamma, \delta$, and $\varepsilon$ [163]. These proteins bind DNA as homo/heterodimers to palindromic GCC(N3)GGC sequences and use N-terminal domains to activate or repress transcription. AP2 $a, \beta$, and $\gamma$ are expressed in neural crest and in facial and limb bud SSCs in the embryo, and direct cell survival and proliferation. AP2 $\alpha$ is also expressed in GPCs and delays cell differentiation. Its inactivation in the mouse leads to severe craniofacial malformations, among other defects. In contrast, inactivation of either AP2 $\beta$ or $\mathbf{A P 2} \gamma$ does not affect chondrogenesis, possibly due to redundancy with family members. AP2 $\varepsilon$ was recently shown to be expressed in HCs and ACCs, and upregulated in human osteoarthritis [164]. Inactivation of its gene in the mouse does not impact chondrogenesis, but protects mice against post-traumatic osteoarthritis. AP2 $\varepsilon$ was proposed to directly contribute to Col2al repression in HCs [165]. Further studies are thus warranted to fully explore the actions and regulation of AP2 proteins in chondrocytes.

\section{Transcription factors with a $\beta$-hairpin exposed by a $a / \beta$-scaffold}

The last TF superclass reviewed here is represented by two classes of proteins that have only remotely related DNA-binding domains: NF1 and SMAD proteins. The NFI class comprises four members (NFIA, NFIB, NFIC, and NFIX) and the SMAD class has eight of them (SMAD1 to 8/9) in mammals. All have important roles in various processes [166] NFI homo/heterodimers bind DNA at the palindromic TTGGC(N5)GCCAA sequence to 
contribute to transcriptional activation or repression. NFIX missense and dominant-negative mutations cause Sotos and Marshall-Smith syndrome, respectively. These disorders include overgrowth and kyphosis, which are also seen in Nfix-null mice [167]. While known to be important in skeleton formation and homeostasus, their expression pattern and roles in chondrocytes remain unclear. SMAD TFs are categorized into co-SMAD (SMAD4), regulatory-SMADs (SMAD1-3, 5 and 8/9), and inhibitory SMADs (SMAD6 and 7). They mediate canonical signaling pathways initiated by members of the TGF $\beta$ superfamily, namely TGF $\beta$ and bone morphogenetic proteins (BMPs). They have important, overlapping roles in cooperation with other TFs, including SOX9 and RUNX2, at virtually every step of skeletal patterning and chondrogenesis $[168,169]$.

\section{Integrative view, perspectives and conclusions}

This review has highlighted that dozens and even perhaps hundreds of TFs control the lineage specification and differentiation activities of chondrocytes and their progenitors and thereby contribute prominently to the great diversity in size, shape and properties of cartilage tissues.

Chondrogenesis starts in prospective skeletal sites of the embryo with the recruitment, lineage commitment and condensation of SSCs. These steps involve a very large number of TFs whose study is challenging due to extensive functional overlap. Patterning factors control cell survival and proliferation spatially and temporally, and are generally distinguished from masters and associated factors, which control lineage determination and differentiation. Some factors, however, may have both types of activities. HOX proteins, PAX1/9, SHOX2, PRRX1, DLX5/6, SOX4/11/12, FOXC1/2, and AP2a/ $/ \gamma / \gamma$ likely fall primarily in the first group, and SOX9, NKX3.2, TWIST1, JUN, SNAI2, and HES/HEY proteins in the second group. Several of these early factors remain expressed in perichondrium cells and JPs during cartilage primordia and growth plate development. They may thus continue to determine skeletal patterning and overt development at those stages. Early chondrocyte differentiation in cartilage primordia is governed by the SOX5/6/9 master trio in concert or in parallel with SP1, PPAR $\gamma, \mathrm{BBF} 2 \mathrm{H} 7$, and CLOCK proteins. RELA, SNAI1/2, FOXO1/3/4, HIF1a, and ATF2/CREB contribute to this step to promote cell proliferation and survival, and possibly also differentiation. During GPC maturation, chondrocytes still rely on SOX5/6/9 to maintain expression of EC markers at the PHC, to repress PHC markers, and to activate HC markers. They also involve ZNF521, NR1A2, SHOX/2, FOXP1/2/4, FOS, and AP2a/e to help the SOX trio. In addition, they require the actions of the RUNX1/2/3 masters to initiate activation of pre-, hypertrophic and terminal markers. These factors are helped with MEF2C/D, ZBTB20, SNAI1/2, SP7, NR1A1, PPAR $\gamma$, TRPS1, DLX5/6, FOXC1/2, FOXA2/3, ATF3/4/6, FOSL2, HES/HEY proteins, c$\mathrm{MAF}$, and $\mathrm{C} / \mathrm{EBP} \beta$. Along with the discovery of GPC regulators, great progress has been made to reveal factors controlling healthy ACC specification, differentiation and maintenance. These factors comprise SOX5/6/9, ERG, NFATC1/2, NKX3.2, PPAR $\gamma$, and CLOCK proteins. Other factors are harmful for these cells. They include ATF3, C/EBP $\beta$, RUNX1/2, NFkB, and PPARס. 
Although already very long and complex, this list of chondrocyte-determining TFs is still far from being definitive. More TFs than discussed here have been found expressed in the chondrocyte lineage and many additional factors likely remain to be uncovered. In addition, important knowledge gaps remain for all factors already listed. A few of the many outstanding questions that need answers are the following. Among the many TFs known to have key roles in SSCs, which ones, if any, are chondrogenic pioneers? Do SOX9 and RUNX proteins have pioneer factor roles in ECs, maturing GPCs and ACCs in addition to classical TF roles? What are the master factors that decisively distinguish the ACC fate from the GPC fate? What is the full targetome of each chondrogenic factor and how does this targetome change as cells progress through successive differentiation stages? How do chondrogenic TFs functionally interact with one another?

Definitive understanding of chondrogenic transcriptional networks will require more studies in vivo and in vitro. Studies on human samples are invaluable to provide direct insights into physiological and pathological processes, but they are insufficient to fully dissect cellular and molecular actions. Among animal models, the mouse has been most often used and should continue to be used. A major advantage of mice is that loss- and gain-of-function assays can be readily controlled spatially and temporally using conditional approaches. This is critical in chondrogenesis to pinpoint cell- and non-cell-autonomous functions and stagespecific functions of TFs. To decode the molecular actions of TFs, ChIP-seq is a state-ofthe-art approach to achieve non-biased characterization of the genome occupancy of TFs. Recent studies have revealed an abundance of chondrocyte-specific super-enhancers bound by the SOX5/6/9 trio and presenting binding motifs for many types of TFs. ChIP-seq should thus ideally be used for every chondrogenic factor and at each stage of chondrocyte differentiation in order to reveal the dynamic changes that likely occur during chondrogenesis in the occupancy of gene regulatory elements by TFs. ChIP-seq studies must be complemented with functional studies, namely RNA-seq in loss- and gain-of-function models, reporter assays with relevant enhancers and promoter segments, and protein-protein interaction assays. Beyond studying the genomic actions of TFs, it is also important to characterize the multiple levels of regulation of these factors. These levels include the epigenetic control of chromatin as well as transcriptional, posttranscriptional and posttranslational regulation. One should also take into consideration that various types of non-coding RNAs are implicated in transcriptional regulation and that many TFs have nontranscriptional roles that can also critically influence cell fate and differentiation.

In conclusion, the last two decades have allowed a wealth of discoveries to be made in the molecular control of chondrogenesis, and this has included the revelation that the pathway is driven and kept in check by dozens of TFs. Key nodes in transcriptional hierarchies and networks have started to be established, and genomic hubs in the form of super-enhancers have started to be located within and around cartilage-specific genes. However, gaps in knowledge remain at multiple levels. Guided by all notable milestones already achieved, prompted by novel ideas, and supported by ever-evolving technological capabilities, researchers of the next decade are well equipped to reach full understanding of chondrogenic transcriptional networks and full understanding of the interactions of these networks with other regulatory pathways, to apply acquired knowledge to fully decipher molecular 
mechanisms disrupted in cartilage malformation and degeneration diseases, and to design efficient approaches to prevent, treat and cure these diseases.

\section{Acknowledgments}

Work by the authors described in this review was supported by grants from the National Institute of Arthritis and Musculoskeletal and Skin Diseases AR46249, AR54153, and AR60016 to VL, and AR068361 to GZ, and by a Lerner Research Institute Morgenthaler Postdoctoral Fellowship to CFL.
Abbreviations
AC articular cartilage
ACC articular chondrocyte
CC columnar chondrocyte
EC early chondrocyte
EO endochondral ossification
GP growth plate
GPC growth plate chondrocyte
HC hypertrophic chondrocyte
JP joint progenitor cells
OB osteoblast
OCP osteochondroprogenitor
PC prechondrocyte
PHC prehypertrophic chondrocyte
SSC skeletal progenitor/stem cell
TC terminal chondrocyte
TF transcription factor

\section{References}

1. Kozhemyakina E, Lassar AB, Zelzer E. A pathway to bone: signaling molecules and transcription factors involved in chondrocyte development and maturation. Development. 2015; 142:817-31. [PubMed: 25715393]

2. Bonafe L, Cormier-Daire V, Hall C, Lachman R, Mortier G, Mundlos S, et al. Nosology and classification of genetic skeletal disorders: 2015 revision. American journal of medical genetics Part A. 2015; 167A:2869-92. [PubMed: 26394607]

3. Allen KD, Golightly YM. State of the evidence. Curr Opin Rheumatol. 2015; 27:276-83. [PubMed: 25775186]

4. Decker RS, Koyama E, Pacifici M. Articular Cartilage: Structural and Developmental Intricacies and Questions. Curr Osteoporos Rep. 2015; 13:407-14. [PubMed: 26408155] 
5. Lassar AB, Paterson BM, Weintraub H. Transfection of a DNA locus that mediates the conversion of 10T1/2 fibroblasts to myoblasts. Cell. 1986; 47:649-56. [PubMed: 2430720]

6. Bell DM, Leung KK, Wheatley SC, Ng LJ, Zhou S, Ling KW, et al. SOX9 directly regulates the type-II collagen gene. Nature genetics. 1997; 16:174-8. [PubMed: 9171829]

7. Lefebvre V, Huang W, Harley VR, Goodfellow PN, de Crombrugghe B. SOX9 is a potent activator of the chondrocyte-specific enhancer of the pro alpha1(II) collagen gene. Molecular and cellular biology. 1997; 17:2336-46. [PubMed: 9121483]

8. Komori T, Yagi H, Nomura S, Yamaguchi A, Sasaki K, Deguchi K, et al. Targeted disruption of Cbfa1 results in a complete lack of bone formation owing to maturational arrest of osteoblasts. Cell. 1997; 89:755-64. [PubMed: 9182763]

9. Takeda S, Bonnamy JP, Owen MJ, Ducy P, Karsenty G. Continuous expression of Cbfa1 in nonhypertrophic chondrocytes uncovers its ability to induce hypertrophic chondrocyte differentiation and partially rescues Cbfa1-deficient mice. Genes \& development. 2001; 15:467-81. [PubMed: 11230154]

10. Yoshida CA, Yamamoto H, Fujita T, Furuichi T, Ito K, Inoue K, et al. Runx2 and Runx3 are essential for chondrocyte maturation, and Runx2 regulates limb growth through induction of Indian hedgehog. Genes \& development. 2004; 18:952-63. [PubMed: 15107406]

11. Iwafuchi-Doi M, Zaret KS. Cell fate control by pioneer transcription factors. Development. 2016; 143:1833-7. [PubMed: 27246709]

12. Takahashi K, Yamanaka S. Induction of pluripotent stem cells from mouse embryonic and adult fibroblast cultures by defined factors. Cell. 2006; 126:663-76. [PubMed: 16904174]

13. Whyte WA, Orlando DA, Hnisz D, Abraham BJ, Lin CY, Kagey MH, et al. Master transcription factors and mediator establish super-enhancers at key cell identity genes. Cell. 2013; 153:307-19. [PubMed: 23582322]

14. Liu CF, Lefebvre V. The transcription factors SOX9 and SOX5/SOX6 cooperate genome-wide through super-enhancers to drive chondrogenesis. Nucleic acids research. 2015; 43:8183-203. [PubMed: 26150426]

15. Ohba S, He X, Hojo H, McMahon AP. Distinct Transcriptional Programs Underlie Sox9 Regulation of the Mammalian Chondrocyte. Cell Rep. 2015; 12:229-43. [PubMed: 26146088]

16. Wingender E, Schoeps T, Haubrock M, Donitz J. TFClass: a classification of human transcription factors and their rodent orthologs. Nucleic acids research. 2015; 43:D97-102. [PubMed: 25361979]

17. Kamachi Y, Kondoh H. Sox proteins: regulators of cell fate specification and differentiation. Development. 2013; 140:4129-44. [PubMed: 24086078]

18. Foster JW, Dominguez-Steglich MA, Guioli S, Kwok C, Weller PA, Stevanovic M, et al. Campomelic dysplasia and autosomal sex reversal caused by mutations in an SRY-related gene. Nature. 1994; 372:525-30. [PubMed: 7990924]

19. Wagner T, Wirth J, Meyer J, Zabel B, Held M, Zimmer J, et al. Autosomal sex reversal and campomelic dysplasia are caused by mutations in and around the SRY-related gene SOX9. Cell. 1994; 79:1111-20. [PubMed: 8001137]

20. Akiyama H, Chaboissier MC, Martin JF, Schedl A, de Crombrugghe B. The transcription factor Sox9 has essential roles in successive steps of the chondrocyte differentiation pathway and is required for expression of Sox 5 and Sox6. Genes \& development. 2002; 16:2813-28. [PubMed: 12414734]

21. Bi W, Deng JM, Zhang Z, Behringer RR, de Crombrugghe B. Sox9 is required for cartilage formation. Nature genetics. 1999; 22:85-9. [PubMed: 10319868]

22. Ikegami D, Akiyama H, Suzuki A, Nakamura T, Nakano T, Yoshikawa H, et al. Sox9 sustains chondrocyte survival and hypertrophy in part through Pik3ca-Akt pathways. Development. 2011; 138:1507-19. [PubMed: 21367821]

23. Dy P, Wang W, Bhattaram P, Wang Q, Wang L, Ballock RT, et al. Sox9 directs hypertrophic maturation and blocks osteoblast differentiation of growth plate chondrocytes. Developmental cell. 2012; 22:597-609. [PubMed: 22421045] 
24. Leung VY, Gao B, Leung KK, Melhado IG, Wynn SL, Au TY, et al. SOX9 governs differentiation stage-specific gene expression in growth plate chondrocytes via direct concomitant transactivation and repression. PLoS genetics. 2011; 7:e1002356. [PubMed: 22072985]

25. Henry SP, Liang S, Akdemir KC, de Crombrugghe B. The postnatal role of Sox 9 in cartilage. Journal of bone and mineral research : the official journal of the American Society for Bone and Mineral Research. 2012; 27:2511-25.

26. Smits P, Li P, Mandel J, Zhang Z, Deng JM, Behringer RR, et al. The transcription factors L-Sox5 and Sox6 are essential for cartilage formation. Developmental cell. 2001; 1:277-90. [PubMed: 11702786]

27. Dy P, Smits P, Silvester A, Penzo-Mendez A, Dumitriu B, Han Y, et al. Synovial joint morphogenesis requires the chondrogenic action of Sox 5 and Sox6 in growth plate and articular cartilage. Developmental biology. 2010; 341:346-59. [PubMed: 20206616]

28. Ikeda T, Kamekura S, Mabuchi A, Kou I, Seki S, Takato T, et al. The combination of SOX5, SOX6, and SOX9 (the SOX trio) provides signals sufficient for induction of permanent cartilage. Arthritis and rheumatism. 2004; 50:3561-73. [PubMed: 15529345]

29. Lamb AN, Rosenfeld JA, Neill NJ, Talkowski ME, Blumenthal I, Girirajan S, et al. Haploinsufficiency of SOX5 at 12p12. 1 is associated with developmental delays with prominent language delay, behavior problems, and mild dysmorphic features. Human mutation. 2012; 33:728-40. [PubMed: 22290657]

30. Chimal-Monroy J, Rodriguez-Leon J, Montero JA, Ganan Y, Macias D, Merino R, et al. Analysis of the molecular cascade responsible for mesodermal limb chondrogenesis: Sox genes and BMP signaling. Developmental biology. 2003; 257:292-301. [PubMed: 12729559]

31. Herlofsen SR, Hoiby T, Cacchiarelli D, Zhang X, Mikkelsen TS, Brinchmann JE. Brief report: importance of SOX8 for in vitro chondrogenic differentiation of human mesenchymal stromal cells. Stem cells. 2014; 32:1629-35. [PubMed: 24449344]

32. Schmidt K, Schinke T, Haberland M, Priemel M, Schilling AF, Mueldner C, et al. The high mobility group transcription factor Sox 8 is a negative regulator of osteoblast differentiation. The Journal of cell biology. 2005; 168:899-910. [PubMed: 15753123]

33. Sock E, Schmidt K, Hermanns-Borgmeyer I, Bosl MR, Wegner M. Idiopathic weight reduction in mice deficient in the high-mobility-group transcription factor Sox8. Molecular and cellular biology. 2001; 21:6951-9. [PubMed: 11564878]

34. Bhattaram P, Penzo-Mendez A, Kato K, Bandyopadhyay K, Gadi A, Taketo MM, et al. SOXC proteins amplify canonical WNT signaling to secure nonchondrocytic fates in skeletogenesis. The Journal of cell biology. 2014; 207:657-71. [PubMed: 25452386]

35. Bhattaram P, Penzo-Mendez A, Sock E, Colmenares C, Kaneko KJ, Vassilev A, et al. Organogenesis relies on SoxC transcription factors for the survival of neural and mesenchymal progenitors. Nature communications. 2010; 1:9.

36. Kato K, Bhattaram P, Penzo-Mendez A, Gadi A, Lefebvre V. SOXC Transcription Factors Induce Cartilage Growth Plate Formation in Mouse Embryos by Promoting Noncanonical WNT Signaling. Journal of bone and mineral research : the official journal of the American Society for Bone and Mineral Research. 2015; 30:1560-71.

37. Cadigan KM, Waterman ML. TCF/LEFs and Wnt signaling in the nucleus. Cold Spring Harb Perspect Biol. 2012:4.

38. Sgariglia F, Pedrini E, Bradfield JP, Bhatti TR, D'Adamo P, Dormans JP, et al. The type 2 diabetes associated rs7903146 T allele within TCF7L2 is significantly under-represented in Hereditary Multiple Exostoses: insights into pathogenesis. Bone. 2015; 72:123-7. [PubMed: 25498973]

39. Mikasa M, Rokutanda S, Komori H, Ito K, Tsang YS, Date Y, et al. Regulation of Tcf7 by Runx2 in chondrocyte maturation and proliferation. Journal of bone and mineral metabolism. 2011; 29:291-9. [PubMed: 20890621]

40. Ma B, Zhong L, van Blitterswijk CA, Post JN, Karperien M. T cell factor 4 is a pro-catabolic and apoptotic factor in human articular chondrocytes by potentiating nuclear factor kappaB signaling. The Journal of biological chemistry. 2013; 288:17552-8. [PubMed: 23603903] 
41. Usami Y, Gunawardena AT, Iwamoto M, Enomoto-Iwamoto M. Wnt signaling in cartilage development and diseases: lessons from animal studies. Laboratory investigation; a journal of technical methods and pathology. 2016; 96:186-96. [PubMed: 26641070]

42. Cohen MM Jr. Perspectives on RUNX genes: an update. American journal of medical genetics Part A. 2009; 149A:2629-46. [PubMed: 19830829]

43. Liu TM, Lee EH. Transcriptional regulatory cascades in Runx2-dependent bone development. Tissue Eng Part B Rev. 2013; 19:254-63. [PubMed: 23150948]

44. Inada M, Yasui T, Nomura S, Miyake S, Deguchi K, Himeno M, et al. Maturational disturbance of chondrocytes in Cbfa1-deficient mice. Developmental dynamics : an official publication of the American Association of Anatomists. 1999; 214:279-90. [PubMed: 10213384]

45. Takarada T, Hinoi E, Nakazato R, Ochi H, Xu C, Tsuchikane A, et al. An analysis of skeletal development in osteoblast-specific and chondrocyte-specific runt-related transcription factor-2 (Runx2) knockout mice. Journal of bone and mineral research : the official journal of the American Society for Bone and Mineral Research. 2013; 28:2064-9.

46. Wu H, Whitfield TW, Gordon JA, Dobson JR, Tai PW, van Wijnen AJ, et al. Genomic occupancy of Runx 2 with global expression profiling identifies a novel dimension to control of osteoblastogenesis. Genome biology. 2014; 15:R52. [PubMed: 24655370]

47. Li F, Lu Y, Ding M, Napierala D, Abbassi S, Chen Y, et al. Runx2 contributes to murine Col10a1 gene regulation through direct interaction with its cis-enhancer. Journal of bone and mineral research : the official journal of the American Society for Bone and Mineral Research. 2011; 26:2899-910.

48. Liakhovitskaia A, Lana-Elola E, Stamateris E, Rice DP, van 't Hof RJ, Medvinsky A. The essential requirement for Runx1 in the development of the sternum. Developmental biology. 2010; 340:539-46. [PubMed: 20152828]

49. Kimura A, Inose H, Yano F, Fujita K, Ikeda T, Sato S, et al. Runx1 and Runx2 cooperate during sternal morphogenesis. Development. 2010; 137:1159-67. [PubMed: 20181744]

50. LeBlanc KT, Walcott ME, Gaur T, O’Connell SL, Basil K, Tadiri CP, et al. Runx1 Activities in Superficial Zone Chondrocytes, Osteoarthritic Chondrocyte Clones and Response to Mechanical Loading. J Cell Physiol. 2015; 230:440-8. [PubMed: 25078095]

51. Tian F, Wu M, Deng L, Zhu G, Ma J, Gao B, et al. Core binding factor beta (Cbfbeta) controls the balance of chondrocyte proliferation and differentiation by upregulating Indian hedgehog (Ihh) expression and inhibiting parathyroid hormone-related protein receptor (PPR) expression in postnatal cartilage and bone formation. Journal of bone and mineral research : the official journal of the American Society for Bone and Mineral Research. 2014; 29:1564-74.

52. Park NR, Lim KE, Han MS, Che X, Park CY, Kim JE, et al. Core Binding Factor beta Plays a Critical Role During Chondrocyte Differentiation. J Cell Physiol. 2016; 231:162-71. [PubMed: 26058470]

53. Potthoff MJ, Olson EN. MEF2: a central regulator of diverse developmental programs. Development. 2007; 134:4131-40. [PubMed: 17959722]

54. Verzi MP, Agarwal P, Brown C, McCulley DJ, Schwarz JJ, Black BL. The transcription factor MEF2C is required for craniofacial development. Developmental cell. 2007; 12:645-52. [PubMed: 17420000]

55. Arnold MA, Kim Y, Czubryt MP, Phan D, McAnally J, Qi X, et al. MEF2C transcription factor controls chondrocyte hypertrophy and bone development. Developmental cell. 2007; 12:377-89. [PubMed: 17336904]

56. O'Dea E, Hoffmann A. The regulatory logic of the NF-kappaB signaling system. Cold Spring Harb Perspect Biol. 2010; 2:a000216. [PubMed: 20182598]

57. Murakami S, Lefebvre V, de Crombrugghe B. Potent inhibition of the master chondrogenic factor Sox 9 gene by interleukin-1 and tumor necrosis factor-alpha. The Journal of biological chemistry. 2000; 275:3687-92. [PubMed: 10652367]

58. Park M, Yong Y, Choi SW, Kim JH, Lee JE, Kim DW. Constitutive RelA activation mediated by Nkx3. 2 controls chondrocyte viability. Nat Cell Biol. 2007; 9:287-98. [PubMed: 17310243]

59. Wu S, Morrison A, Sun H, De Luca F. Nuclear factor-kappaB (NF-kappaB) p65 interacts with $\mathrm{Stat} 5 \mathrm{~b}$ in growth plate chondrocytes and mediates the effects of growth hormone on 
chondrogenesis and on the expression of insulin-like growth factor-1 and bone morphogenetic protein-2. The Journal of biological chemistry. 2011; 286:24726-34. [PubMed: 21592969]

60. Wu H, Peisley A, Graef IA, Crabtree GR. NFAT signaling and the invention of vertebrates. Trends Cell Biol. 2007; 17:251-60. [PubMed: 17493814]

61. Tomita M, Reinhold MI, Molkentin JD, Naski MC. Calcineurin and NFAT4 induce chondrogenesis. The Journal of biological chemistry. 2002; 277:42214-8. [PubMed: 12239209]

62. Greenblatt MB, Ritter SY, Wright J, Tsang K, Hu D, Glimcher LH, et al. NFATc1 and NFATc2 repress spontaneous osteoarthritis. Proceedings of the National Academy of Sciences of the United States of America. 2013; 110:19914-9. [PubMed: 24248346]

63. Wang J, Gardner BM, Lu Q, Rodova M, Woodbury BG, Yost JG, et al. Transcription factor Nfat 1 deficiency causes osteoarthritis through dysfunction of adult articular chondrocytes. The Journal of pathology. 2009; 219:163-72. [PubMed: 19526482]

64. Legeai-Mallet L, Benoist-Lasselin C, Munnich A, Bonaventure J. Overexpression of FGFR3, Stat1, Stat5 and p21Cip1 correlates with phenotypic severity and defective chondrocyte differentiation in FGFR3-related chondrodysplasias. Bone. 2004; 34:26-36. [PubMed: 14751560]

65. Sahni M, Ambrosetti DC, Mansukhani A, Gertner R, Levy D, Basilico C. FGF signaling inhibits chondrocyte proliferation and regulates bone development through the STAT-1 pathway. Genes \& development. 1999; 13:1361-6. [PubMed: 10364154]

66. Kondo M, Yamaoka K, Sakata K, Sonomoto K, Lin L, Nakano K, et al. Contribution of the Interleukin-6/STAT-3 Signaling Pathway to Chondrogenic Differentiation of Human Mesenchymal Stem Cells. Arthritis \& rheumatology. 2015; 67:1250-60. [PubMed: 25604648]

67. Legendre F, Dudhia J, Pujol JP, Bogdanowicz P. JAK/STAT but not ERK1/ERK2 pathway mediates interleukin (IL)-6/soluble IL-6R down-regulation of Type II collagen, aggrecan core, and link protein transcription in articular chondrocytes. Association with a down-regulation of SOX9 expression. The Journal of biological chemistry. 2003; 278:2903-12. [PubMed: 12419823]

68. Razin SV, Borunova VV, Maksimenko OG, Kantidze OL. Cys2His2 zinc finger protein family: classification, functions, and major members. Biochemistry (Mosc). 2012; 77:217-26. [PubMed: 22803940]

69. Gupta RM, Musunuru K. Expanding the genetic editing tool kit: ZFNs, TALENs, and CRISPRCas9. The Journal of clinical investigation. 2014; 124:4154-61. [PubMed: 25271723]

70. Chadjichristos C, Ghayor C, Kypriotou M, Martin G, Renard E, Ala-Kokko L, et al. Sp1 and Sp3 transcription factors mediate interleukin-1 beta down-regulation of human type II collagen gene expression in articular chondrocytes. The Journal of biological chemistry. 2003; 278:39762-72. [PubMed: 12888570]

71. Piera-Velazquez S, Hawkins DF, Whitecavage MK, Colter DC, Stokes DG, Jimenez SA. Regulation of the human SOX9 promoter by Sp1 and CREB. Exp Cell Res. 2007; 313:1069-79. [PubMed: 17289023]

72. Savagner P, Krebsbach PH, Hatano O, Miyashita T, Liebman J, Yamada Y. Collagen II promoter and enhancer interact synergistically through $\mathrm{Sp} 1$ and distinct nuclear factors. DNA Cell Biol. 1995; 14:501-10. [PubMed: 7598805]

73. Nakashima K, Zhou X, Kunkel G, Zhang Z, Deng JM, Behringer RR, et al. The novel zinc fingercontaining transcription factor osterix is required for osteoblast differentiation and bone formation. Cell. 2002; 108:17-29. [PubMed: 11792318]

74. Oh JH, Park SY, de Crombrugghe B, Kim JE. Chondrocyte-specific ablation of Osterix leads to impaired endochondral ossification. Biochem Biophys Res Commun. 2012; 418:634-40. [PubMed: 22290230]

75. Correa D, Hesse E, Seriwatanachai D, Kiviranta R, Saito H, Yamana K, et al. Zfp521 is a target gene and key effector of parathyroid hormone-related peptide signaling in growth plate chondrocytes. Developmental cell. 2010; 19:533-46. [PubMed: 20951345]

76. Seriwatanachai D, Densmore MJ, Sato T, Correa D, Neff L, Baron R, et al. Deletion of Zfp521 rescues the growth plate phenotype in a mouse model of Jansen metaphyseal chondrodysplasia. FASEB J. 2011; 25:3057-67. [PubMed: 21642473] 
77. Zhao H, Zhou W, Yao Z, Wan Y, Cao J, Zhang L, et al. Foxp1/2/4 regulate endochondral ossification as a suppresser complex. Developmental biology. 2015; 398:242-54. [PubMed: 25527076]

78. Lamouille S, Xu J, Derynck R. Molecular mechanisms of epithelial-mesenchymal transition. Nat Rev Mol Cell Biol. 2014; 15:178-96. [PubMed: 24556840]

79. Chen Y, Gridley T. Compensatory regulation of the Snai1 and Snai2 genes during chondrogenesis. Journal of bone and mineral research : the official journal of the American Society for Bone and Mineral Research. 2013; 28:1412-21.

80. de Frutos CA, Vega S, Manzanares M, Flores JM, Huertas H, Martinez-Frias ML, et al. Snail1 is a transcriptional effector of FGFR3 signaling during chondrogenesis and achondroplasias. Developmental cell. 2007; 13:872-83. [PubMed: 18061568]

81. Piva R, Lambertini E, Manferdini C, Capanni C, Penolazzi L, Gabusi E, et al. Slug transcription factor and nuclear Lamin B1 are upregulated in osteoarthritic chondrocytes. Osteoarthritis and cartilage / OARS, Osteoarthritis Research Society. 2015; 23:1226-30.

82. Alman BA. The role of hedgehog signalling in skeletal health and disease. Nat Rev Rheumatol. 2015; 11:552-60. [PubMed: 26077918]

83. Rauch A, Seitz S, Baschant U, Schilling AF, Illing A, Stride B, et al. Glucocorticoids suppress bone formation by attenuating osteoblast differentiation via the monomeric glucocorticoid receptor. Cell Metab. 2010; 11:517-31. [PubMed: 20519123]

84. Tu J, Henneicke H, Zhang Y, Stoner S, Cheng TL, Schindeler A, et al. Disruption of glucocorticoid signaling in chondrocytes delays metaphyseal fracture healing but does not affect normal cartilage and bone development. Bone. 2014; 69:12-22. [PubMed: 25193158]

85. Hartmann K, Koenen M, Schauer S, Wittig-Blaich S, Ahmad M, Baschant U, et al. Molecular Actions of Glucocorticoids in Cartilage and Bone During Health, Disease, and Steroid Therapy. Physiological reviews. 2016; 96:409-47. [PubMed: 26842265]

86. Kim HY, Mohan S. Role and Mechanisms of Actions of Thyroid Hormone on the Skeletal Development. Bone research. 2013; 1:146-61. [PubMed: 26273499]

87. Williams JA, Kondo N, Okabe T, Takeshita N, Pilchak DM, Koyama E, et al. Retinoic acid receptors are required for skeletal growth, matrix homeostasis and growth plate function in postnatal mouse. Developmental biology. 2009; 328:315-27. [PubMed: 19389355]

88. Monemdjou R, Vasheghani F, Fahmi H, Perez G, Blati M, Taniguchi N, et al. Association of cartilage-specific deletion of peroxisome proliferator-activated receptor gamma with abnormal endochondral ossification and impaired cartilage growth and development in a murine model. Arthritis and rheumatism. 2012; 64:1551-61. [PubMed: 22131019]

89. Vasheghani F, Zhang Y, Li YH, Blati M, Fahmi H, Lussier B, et al. PPARgamma deficiency results in severe, accelerated osteoarthritis associated with aberrant mTOR signalling in the articular cartilage. Ann Rheum Dis. 2015; 74:569-78. [PubMed: 25573665]

90. Ratneswaran A, LeBlanc EA, Walser E, Welch I, Mort JS, Borradaile N, et al. Peroxisome proliferator-activated receptor delta promotes the progression of posttraumatic osteoarthritis in a mouse model. Arthritis \& rheumatology. 2015; 67:454-64. [PubMed: 25331977]

91. Chlon TM, Crispino JD. Combinatorial regulation of tissue specification by GATA and FOG factors. Development. 2012; 139:3905-16. [PubMed: 23048181]

92. Alexandrovich A, Qureishi A, Coudert AE, Zhang L, Grigoriadis AE, Shah AM, et al. A role for GATA-6 in vertebrate chondrogenesis. Developmental biology. 2008; 314:457-70. [PubMed: 18191120]

93. Kozhemyakina E, Ionescu A, Lassar AB. GATA6 is a crucial regulator of Shh in the limb bud. PLoS genetics. 2014; 10:e1004072. [PubMed: 24415953]

94. Napierala D, Sam K, Morello R, Zheng Q, Munivez E, Shivdasani RA, et al. Uncoupling of chondrocyte differentiation and perichondrial mineralization underlies the skeletal dysplasia in tricho-rhino-phalangeal syndrome. Hum Mol Genet. 2008; 17:2244-54. [PubMed: 18424451]

95. Wuelling M, Kaiser FJ, Buelens LA, Braunholz D, Shivdasani RA, Depping R, et al. Trps1, a regulator of chondrocyte proliferation and differentiation, interacts with the activator form of Gli3. Developmental biology. 2009; 328:40-53. [PubMed: 19389374] 
96. Burglin TR, Affolter M. Homeodomain proteins: an update. Chromosoma. 2016; 125:497-521. [PubMed: 26464018]

97. Hrycaj SM, Wellik DM. Hox genes and evolution. F1000Research. 2016:5.

98. Pineault KM, Wellik DM. Hox genes and limb musculoskeletal development. Curr Osteoporos Rep. 2014; 12:420-7. [PubMed: 25266923]

99. Fromental-Ramain C, Warot X, Messadecq N, LeMeur M, Dolle P, Chambon P. Hoxa-13 and Hoxd-13 play a crucial role in the patterning of the limb autopod. Development. 1996; 122:29973011. [PubMed: 8898214]

100. Wellik DM, Capecchi MR. Hox10 and Hox11 genes are required to globally pattern the mammalian skeleton. Science. 2003; 301:363-7. [PubMed: 12869760]

101. Goodman FR. Limb malformations and the human HOX genes. American journal of medical genetics. 2002; 112:256-65. [PubMed: 12357469]

102. Binder, G., Rappold, GA. SHOX Deficiency Disorders. In: Pagon, RA.Adam, MP.Ardinger, HH.Wallace, SE.Amemiya, A.Bean, LJH., et al., editors. GeneReviews(R). Seattle (WA): 1993.

103. Bobick BE, Cobb J. Shox 2 regulates progression through chondrogenesis in the mouse proximal limb. Journal of cell science. 2012; 125:6071-83. [PubMed: 23038774]

104. Sergi C, Kamnasaran D. PRRX1 is mutated in a fetus with agnathia-otocephaly. Clin Genet. 2011; 79:293-5. [PubMed: 21294718]

105. Martin JF, Bradley A, Olson EN. The paired-like homeo box gene MHox is required for early events of skeletogenesis in multiple lineages. Genes \& development. 1995; 9:1237-49. [PubMed: 7758948]

106. Shamseldin HE, Faden MA, Alashram W, Alkuraya FS. Identification of a novel DLX5 mutation in a family with autosomal recessive split hand and foot malformation. J Med Genet. 2012; 49:16-20. [PubMed: 22121204]

107. Depew MJ, Lufkin T, Rubenstein JL. Specification of jaw subdivisions by Dlx genes. Science. 2002; 298:381-5. [PubMed: 12193642]

108. Robledo RF, Rajan L, Li X, Lufkin T. The Dlx5 and Dlx6 homeobox genes are essential for craniofacial, axial, and appendicular skeletal development. Genes \& development. 2002; 16:1089-101. [PubMed: 12000792]

109. Zhu H, Bendall AJ. Dlx5 Is a cell autonomous regulator of chondrocyte hypertrophy in mice and functionally substitutes for Dlx6 during endochondral ossification. PloS one. 2009; 4:e8097. [PubMed: 19956613]

110. Hojo H, Ohba S, He X, Lai LP, McMahon AP. Sp7/Osterix Is Restricted to Bone-Forming Vertebrates where It Acts as a Dlx Co-factor in Osteoblast Specification. Developmental cell. 2016; 37:238-53. [PubMed: 27134141]

111. Rainbow RS, Won HK, Zeng L. The role of Nkx3. 2 in chondrogenesis. Front Biol (Beijing). 2014; 9:376-81. [PubMed: 27158253]

112. Hellemans J, Simon M, Dheedene A, Alanay Y, Mihci E, Rifai L, et al. Homozygous inactivating mutations in the NKX3-2 gene result in spondylo-megaepiphyseal-metaphyseal dysplasia. American journal of human genetics. 2009; 85:916-22. [PubMed: 20004766]

113. Zeng L, Kempf H, Murtaugh LC, Sato ME, Lassar AB. Shh establishes an Nkx3. 2/Sox9 autoregulatory loop that is maintained by BMP signals to induce somitic chondrogenesis. Genes \& development. 2002; 16:1990-2005. [PubMed: 12154128]

114. Provot S, Kempf H, Murtaugh LC, Chung UI, Kim DW, Chyung J, et al. Nkx3. 2/Bapx1 acts as a negative regulator of chondrocyte maturation. Development. 2006; 133:651-62. [PubMed: 16421188]

115. Caron MM, Emans PJ, Surtel DA, van der Kraan PM, van Rhijn LW, Welting TJ. BAPX-1/ NKX-3. 2 acts as a chondrocyte hypertrophy molecular switch in osteoarthritis. Arthritis \& rheumatology. 2015; 67:2944-56. [PubMed: 26245691]

116. Mayran A, Pelletier A, Drouin J. Pax factors in transcription and epigenetic remodelling. Semin Cell Dev Biol. 2015; 44:135-44. [PubMed: 26234816]

117. Monsoro-Burq AH. PAX transcription factors in neural crest development. Semin Cell Dev Biol. 2015; 44:87-96. [PubMed: 26410165] 
118. LeClair EE, Bonfiglio L, Tuan RS. Expression of the paired-box genes Pax-1 and Pax-9 in limb skeleton development. Developmental dynamics : an official publication of the American Association of Anatomists. 1999; 214:101-15. [PubMed: 10030590]

119. Peters H, Wilm B, Sakai N, Imai K, Maas R, Balling R. Pax1 and Pax9 synergistically regulate vertebral column development. Development. 1999; 126:5399-408. [PubMed: 10556064]

120. Rodrigo I, Hill RE, Balling R, Munsterberg A, Imai K. Pax1 and Pax9 activate Bapx 1 to induce chondrogenic differentiation in the sclerotome. Development. 2003; 130:473-82. [PubMed: 12490554]

121. Hannenhalli S, Kaestner KH. The evolution of Fox genes and their role in development and disease. Nature reviews Genetics. 2009; 10:233-40.

122. Lam EW, Brosens JJ, Gomes AR, Koo CY. Forkhead box proteins: tuning forks for transcriptional harmony. Nature reviews Cancer. 2013; 13:482-95. [PubMed: 23792361]

123. Kume T, Deng KY, Winfrey V, Gould DB, Walter MA, Hogan BL. The forkhead/winged helix gene Mf1 is disrupted in the pleiotropic mouse mutation congenital hydrocephalus. Cell. 1998; 93:985-96. [PubMed: 9635428]

124. Nifuji A, Miura N, Kato N, Kellermann O, Noda M. Bone morphogenetic protein regulation of forkhead/winged helix transcription factor Foxc2 (Mfh1) in a murine mesodermal cell line C1 and in skeletal precursor cells. Journal of bone and mineral research : the official journal of the American Society for Bone and Mineral Research. 2001; 16:1765-71.

125. Kume T, Jiang H, Topczewska JM, Hogan BL. The murine winged helix transcription factors, Foxc1 and Foxc2, are both required for cardiovascular development and somitogenesis. Genes \& development. 2001; 15:2470-82. [PubMed: 11562355]

126. Motojima M, Tanimoto S, Ohtsuka M, Matsusaka T, Kume T, Abe K. Characterization of Kidney and Skeleton Phenotypes of Mice Double Heterozygous for Foxc1 and Foxc2. Cells Tissues Organs. 2016; 201:380-9. [PubMed: 27193493]

127. Yoshida M, Hata K, Takashima R, Ono K, Nakamura E, Takahata Y, et al. The transcription factor Foxc1 is necessary for Ihh-Gli2-regulated endochondral ossification. Nature communications. 2015; 6:6653.

128. Ionescu A, Kozhemyakina E, Nicolae C, Kaestner KH, Olsen BR, Lassar AB. FoxA family members are crucial regulators of the hypertrophic chondrocyte differentiation program. Developmental cell. 2012; 22:927-39. [PubMed: 22595668]

129. Eelen G, Verlinden L, Maes C, Beullens I, Gysemans C, Paik JH, et al. Forkhead box O transcription factors in chondrocytes regulate endochondral bone formation. The Journal of steroid biochemistry and molecular biology. 2015

130. Akasaki Y, Alvarez-Garcia O, Saito M, Carames B, Iwamoto Y, Lotz MK. FoxO transcription factors support oxidative stress resistance in human chondrocytes. Arthritis \& rheumatology. 2014; 66:3349-58. [PubMed: 25186470]

131. Akasaki Y, Hasegawa A, Saito M, Asahara H, Iwamoto Y, Lotz MK. Dysregulated FOXO transcription factors in articular cartilage in aging and osteoarthritis. Osteoarthritis and cartilage / OARS, Osteoarthritis Research Society. 2014; 22:162-70.

132. Iwamoto M, Tamamura Y, Koyama E, Komori T, Takeshita N, Williams JA, et al. Transcription factor ERG and joint and articular cartilage formation during mouse limb and spine skeletogenesis. Developmental biology. 2007; 305:40-51. [PubMed: 17336282]

133. Ohta Y, Okabe T, Larmour C, Di Rocco A, Maijenburg MW, Phillips A, et al. Articular cartilage endurance and resistance to osteoarthritic changes require transcription factor Erg. Arthritis \& rheumatology. 2015; 67:2679-90. [PubMed: 26097038]

134. Jones S. An overview of the basic helix-loop-helix proteins. Genome biology. 2004; 5:226. [PubMed: 15186484]

135. Miraoui H, Marie PJ. Pivotal role of Twist in skeletal biology and pathology. Gene. 2010; 468:17. [PubMed: 20696219]

136. Reinhold MI, Kapadia RM, Liao Z, Naski MC. The Wnt-inducible transcription factor Twist1 inhibits chondrogenesis. The Journal of biological chemistry. 2006; 281:1381-8. [PubMed: 16293629] 
137. Gu S, Boyer TG, Naski MC. Basic helix-loop-helix transcription factor Twist1 inhibits transactivator function of master chondrogenic regulator Sox9. The Journal of biological chemistry. 2012; 287:21082-92. [PubMed: 22532563]

138. Maes C, Carmeliet G, Schipani E. Hypoxia-driven pathways in bone development, regeneration and disease. Nat Rev Rheumatol. 2012; 8:358-66. [PubMed: 22450551]

139. Amarilio R, Viukov SV, Sharir A, Eshkar-Oren I, Johnson RS, Zelzer E. HIF1alpha regulation of Sox9 is necessary to maintain differentiation of hypoxic prechondrogenic cells during early skeletogenesis. Development. 2007; 134:3917-28. [PubMed: 17913788]

140. Dudek M, Gossan N, Yang N, Im HJ, Ruckshanthi JP, Yoshitane H, et al. The chondrocyte clock gene Bmal1 controls cartilage homeostasis and integrity. The Journal of clinical investigation. 2016; 126:365-76. [PubMed: 26657859]

141. Takarada T, Kodama A, Hotta S, Mieda M, Shimba S, Hinoi E, et al. Clock genes influence gene expression in growth plate and endochondral ossification in mice. The Journal of biological chemistry. 2012; 287:36081-95. [PubMed: 22936800]

142. Rutkowski TP, Kohn A, Sharma D, Ren Y, Mirando AJ, Hilton MJ. HES factors regulate specific aspects of chondrogenesis and chondrocyte hypertrophy during cartilage development. Development. 2016; 143:e1.

143. Patra D, DeLassus E, Liang G, Sandell LJ. Cartilage-specific ablation of site-1 protease in mice results in the endoplasmic reticulum entrapment of type IIb procollagen and down-regulation of cholesterol and lipid homeostasis. PloS one. 2014; 9:e105674. [PubMed: 25147951]

144. Patra D, Xing X, Davies S, Bryan J, Franz C, Hunziker EB, et al. Site-1 protease is essential for endochondral bone formation in mice. The Journal of cell biology. 2007; 179:687-700. [PubMed: 18025304]

145. Horiuchi K, Tohmonda T, Morioka $\mathrm{H}$. The unfolded protein response in skeletal development and homeostasis. Cellular and molecular life sciences : CMLS. 2016; 73:2851-69. [PubMed: 27002737]

146. Yang X, Karsenty G. ATF4, the osteoblast accumulation of which is determined posttranslationally, can induce osteoblast-specific gene expression in non-osteoblastic cells. The Journal of biological chemistry. 2004; 279:47109-14. [PubMed: 15377660]

147. Wang W, Lian N, Li L, Moss HE, Wang W, Perrien DS, et al. Atf4 regulates chondrocyte proliferation and differentiation during endochondral ossification by activating Ihh transcription. Development. 2009; 136:4143-53. [PubMed: 19906842]

148. Iezaki T, Ozaki K, Fukasawa K, Inoue M, Kitajima S, Muneta T, et al. ATF3 deficiency in chondrocytes alleviates osteoarthritis development. The Journal of pathology. 2016; 239:426-37. [PubMed: 27159257]

149. Guo F, Han X, Wu Z, Cheng Z, Hu Q, Zhao Y, et al. ATF6a, a Runx2-activable transcription factor, is a new regulator of chondrocyte hypertrophy. Journal of cell science. 2016; 129:717-28. [PubMed: 26527399]

150. Saito A, Hino S, Murakami T, Kanemoto S, Kondo S, Saitoh M, et al. Regulation of endoplasmic reticulum stress response by a BBF2H7-mediated Sec23a pathway is essential for chondrogenesis. Nat Cell Biol. 2009; 11:1197-204. [PubMed: 19767744]

151. Shaulian E, Karin M. AP-1 as a regulator of cell life and death. Nat Cell Biol. 2002; 4:E131-6. [PubMed: 11988758]

152. He X, Ohba S, Hojo H, McMahon AP. AP-1 family members act with Sox9 to promote chondrocyte hypertrophy. Development. 2016; 143:3012-23. [PubMed: 27471255]

153. Wang ZQ, Ovitt C, Grigoriadis AE, Mohle-Steinlein U, Ruther U, Wagner EF. Bone and haematopoietic defects in mice lacking c-fos. Nature. 1992; 360:741-5. [PubMed: 1465144]

154. Karreth F, Hoebertz A, Scheuch H, Eferl R, Wagner EF. The AP1 transcription factor Fra2 is required for efficient cartilage development. Development. 2004; 131:5717-25. [PubMed: 15509771]

155. Bozec A, Bakiri L, Jimenez M, Schinke T, Amling M, Wagner EF. Fra-2/AP-1 controls bone formation by regulating osteoblast differentiation and collagen production. The Journal of cell biology. 2010; 190:1093-106. [PubMed: 20837772] 
156. Kan A, Tabin CJ. c-Jun is required for the specification of joint cell fates. Genes \& development. 2013; 27:514-24. [PubMed: 23475960]

157. Huang W, Lu N, Eberspaecher H, De Crombrugghe B. A new long form of c-Maf cooperates with Sox 9 to activate the type II collagen gene. The Journal of biological chemistry. 2002; 277:5066875. [PubMed: 12381733]

158. MacLean HE, Kim JI, Glimcher MJ, Wang J, Kronenberg HM, Glimcher LH. Absence of transcription factor c-maf causes abnormal terminal differentiation of hypertrophic chondrocytes during endochondral bone development. Developmental biology. 2003; 262:51-63. [PubMed: 14512017]

159. Sakai M, Imaki J, Yoshida K, Ogata A, Matsushima-Hibaya Y, Kuboki Y, et al. Rat maf related genes: specific expression in chondrocytes, lens and spinal cord. Oncogene. 1997; 14:745-50. [PubMed: 9038383]

160. Okuma T, Hirata M, Yano F, Mori D, Kawaguchi H, Chung UI, et al. Regulation of mouse chondrocyte differentiation by CCAAT/enhancer-binding proteins. Biomed Res. 2015; 36:21-9. [PubMed: 25749148]

161. Hirata M, Kugimiya F, Fukai A, Ohba S, Kawamura N, Ogasawara T, et al. C/EBPbeta Promotes transition from proliferation to hypertrophic differentiation of chondrocytes through transactivation of p57. PloS one. 2009; 4:e4543. [PubMed: 19229324]

162. Ushijima T, Okazaki K, Tsushima H, Ishihara K, Doi T, Iwamoto Y. CCAAT/enhancer binding protein beta regulates expression of Indian hedgehog during chondrocytes differentiation. PloS one. 2014; 9:e104547. [PubMed: 25105964]

163. Wenke AK, Bosserhoff AK. Roles of AP-2 transcription factors in the regulation of cartilage and skeletal development. FEBS J. 2010; 277:894-902. [PubMed: 20050923]

164. Niebler S, Schubert T, Hunziker EB, Bosserhoff AK. Activating enhancer binding protein 2 epsilon (AP-2epsilon)-deficient mice exhibit increased matrix metalloproteinase 13 expression and progressive osteoarthritis development. Arthritis Res Ther. 2015; 17:119. [PubMed: 25964075]

165. Niebler S, Bosserhoff AK. The transcription factor activating enhancer-binding protein epsilon (AP-2epsilon) regulates the core promoter of type II collagen (COL2A1). FEBS J. 2013; 280:1397-408. [PubMed: 23331625]

166. Harris L, Genovesi LA, Gronostajski RM, Wainwright BJ, Piper M. Nuclear factor one transcription factors: Divergent functions in developmental versus adult stem cell populations. Developmental dynamics : an official publication of the American Association of Anatomists. 2015; 244:227-38. [PubMed: 25156673]

167. Driller K, Pagenstecher A, Uhl M, Omran H, Berlis A, Grunder A, et al. Nuclear factor I X deficiency causes brain malformation and severe skeletal defects. Molecular and cellular biology. 2007; 27:3855-67. [PubMed: 17353270]

168. Wang W, Rigueur D, Lyons KM. TGFbeta signaling in cartilage development and maintenance. Birth Defects Res C Embryo Today. 2014; 102:37-51. [PubMed: 24677722]

169. Samsa WE, Zhou X, Zhou G. Signaling pathways regulating cartilage growth plate formation and activity. Semin Cell Dev Biol. 2016 


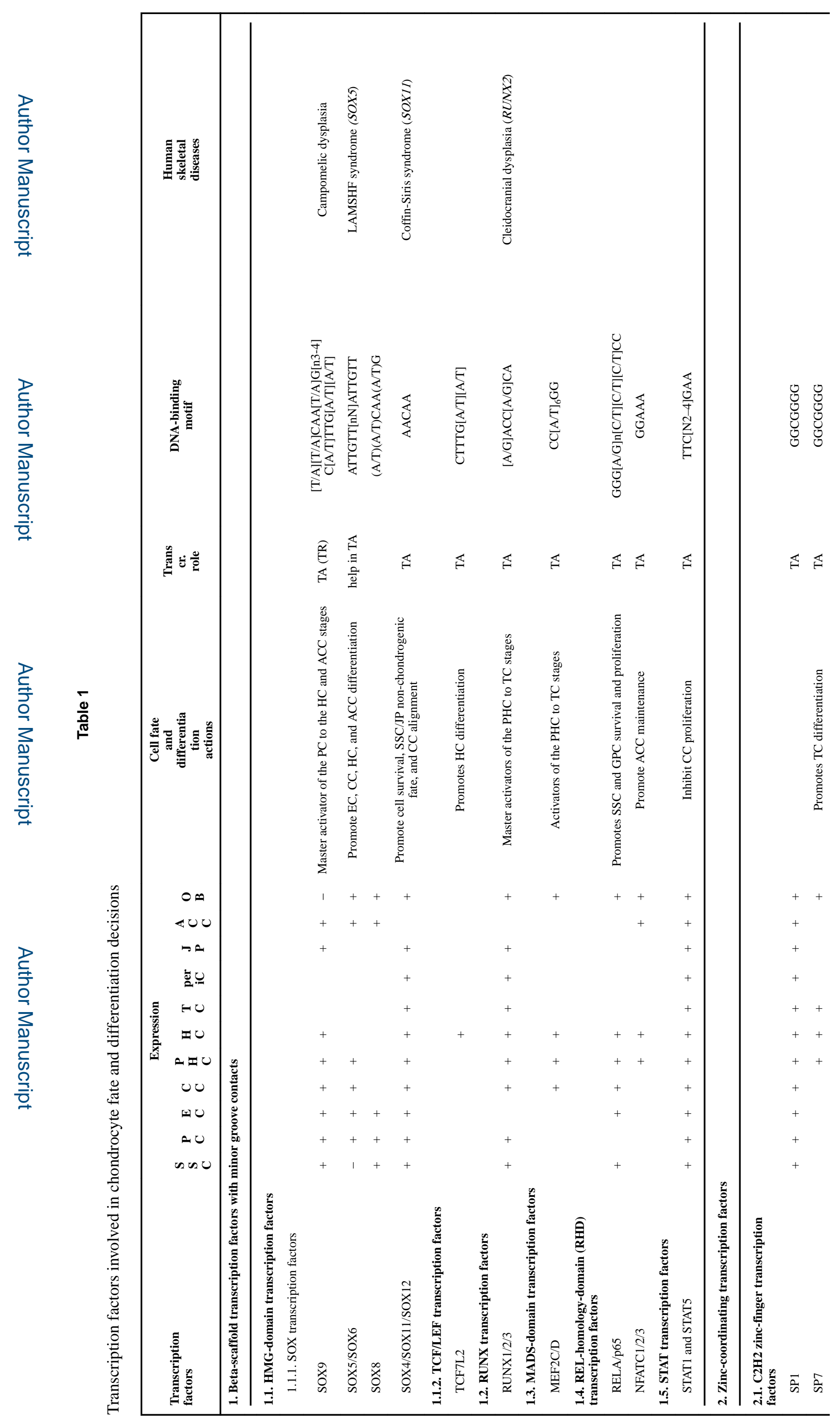




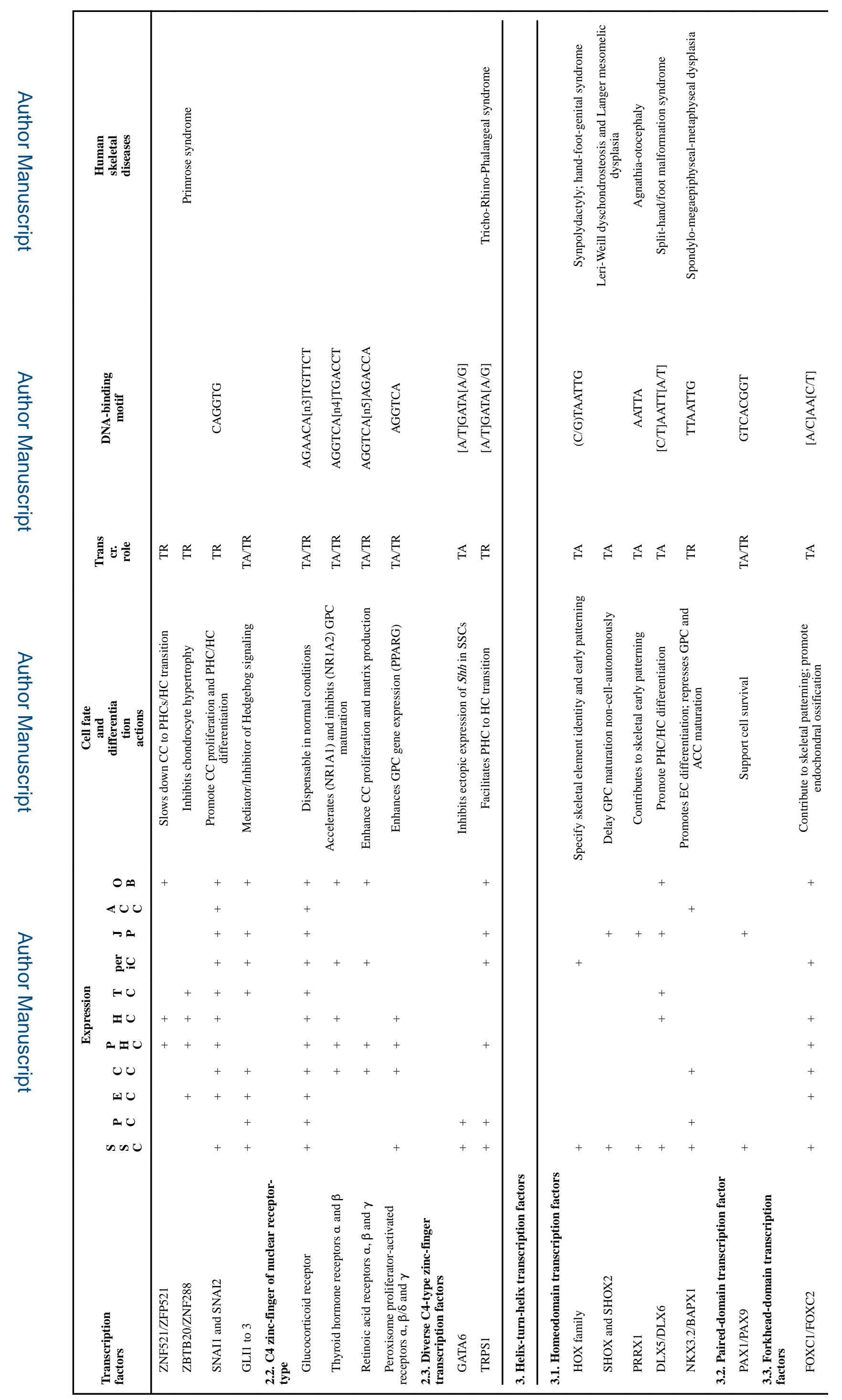




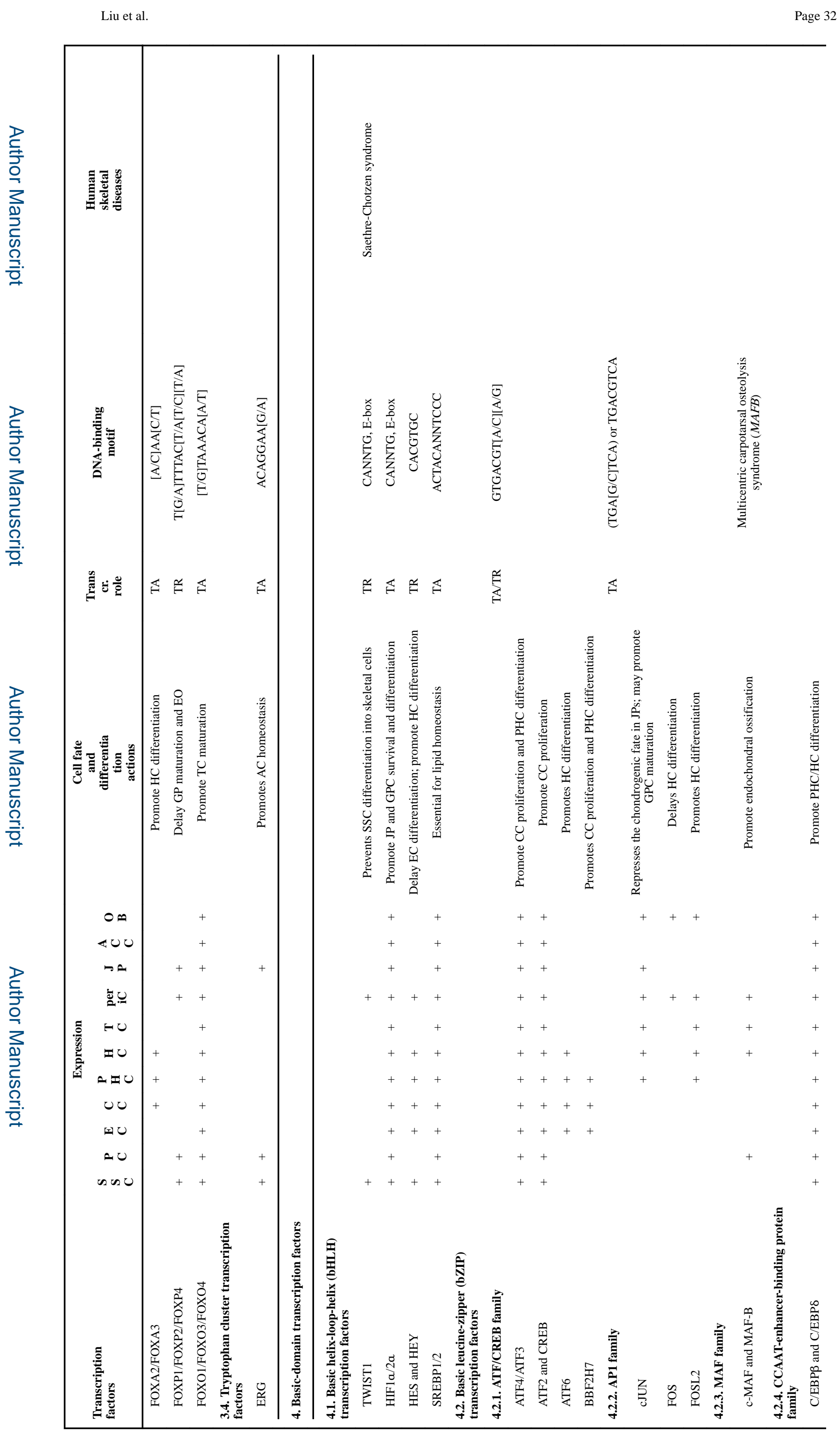

Serin Cell Lev Biol. Author manuscript; available in PMC 2018 February 01. 


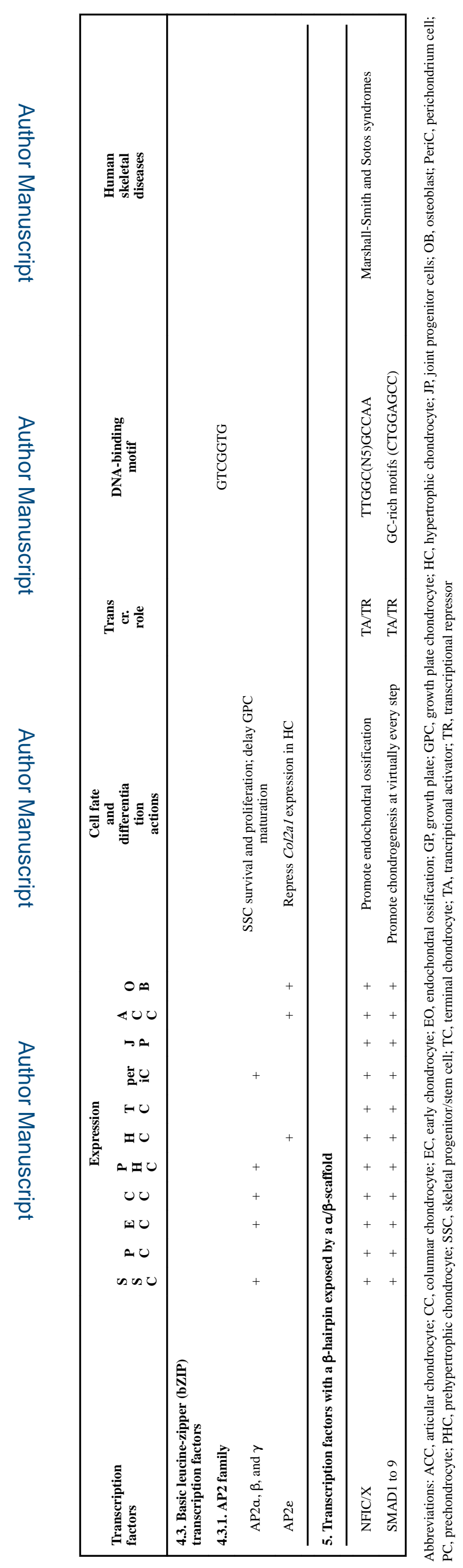

